
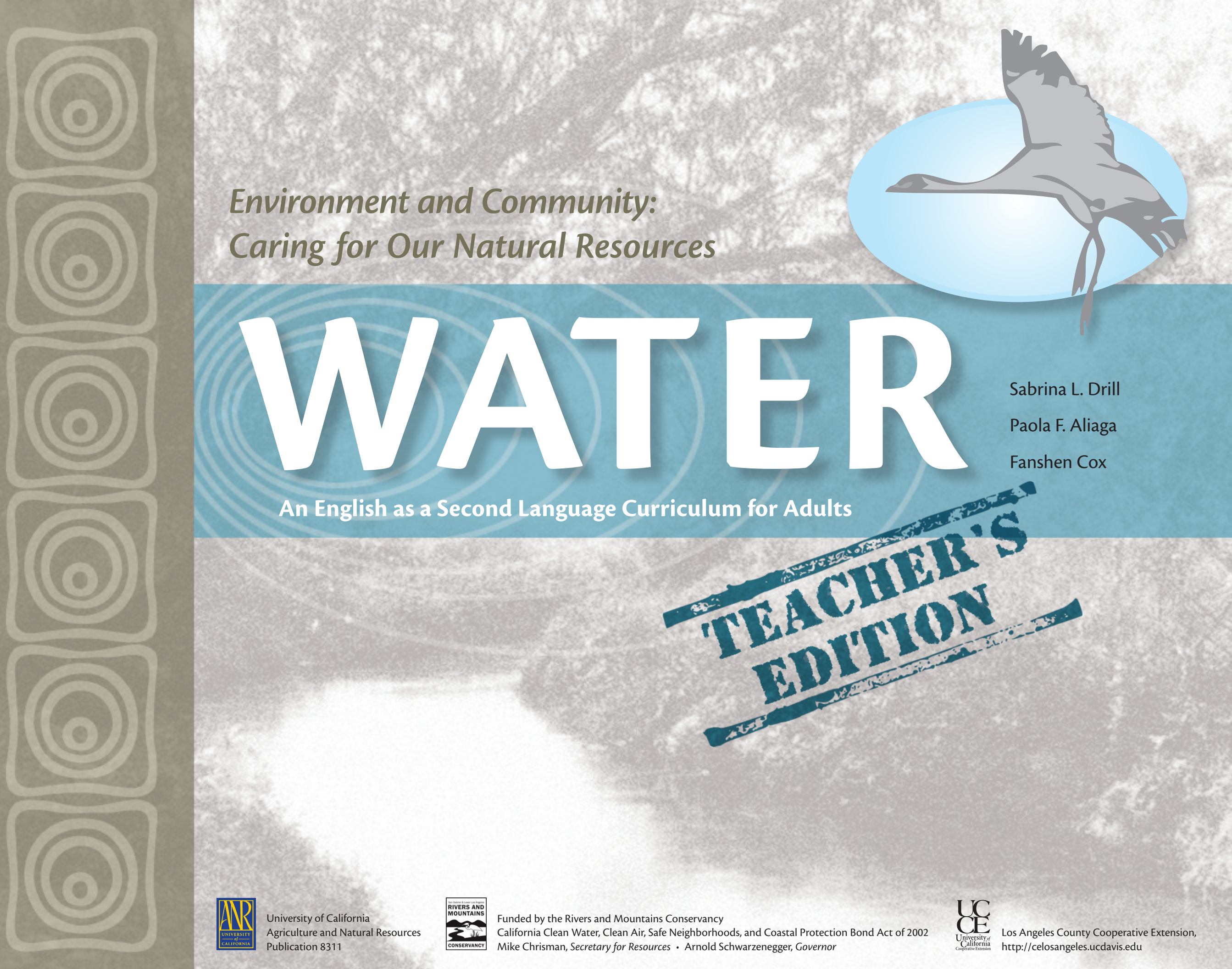


\section{Environment and Community:}

Caring for Our Natural Resources

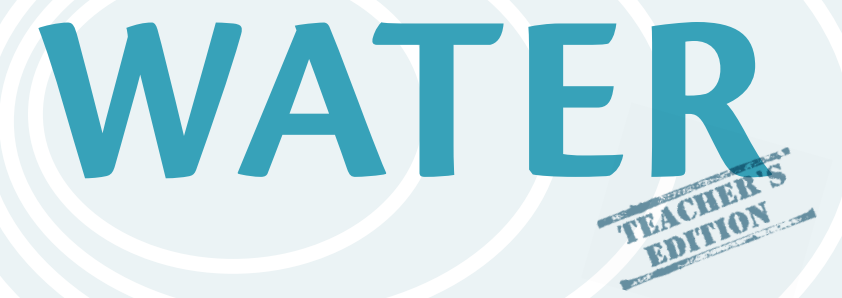

An English as a Second Language Curriculum for Adults

Sabrina L. Drill • Paola F. Aliaga • Fanshen Cox 
To order or obtain ANR publications and other products, visit the ANR Communication Services online catalog at http://anrcatalog. ucdavis.edu or phone 1-800-994-8849. You can also place orders by mail or FAX, or request a printed catalog of our products from

\section{University of California}

Agriculture and Natural Resources

Communication Services

6701 San Pablo Avenue, 2nd Floor

Oakland, California 94608-1239

Telephone 1-800-994-8849

(510) 642-2431

FAX (510) 643-5470

E-mail: danrcs@ucdavis.edu

\section{Publication 8311}

ISBN-13: 978-1-60107-555-0

Design by Robin Walton.

(C)2010 The Regents of the University of California

Division of Agriculture and Natural Resources

All rights reserved.

No part of this publication may be reproduced, stored in a retrieval system, or transmitted, in any form or by any means, electronic, mechanical, photocopying, recording, or otherwise, without the written permission of the publisher and the authors.
The University of California prohibits discrimination or harassment of any person on the basis of race, color, national origin, religion, sex, gender identity, pregnancy (including childbirth, and medical conditions related to pregnancy or childbirth), physical or mental disability, medical condition (cancer-related or genetic characteristics), ancestry, marital status, age, sexual orientation, citizenship, or status as a covered veteran (covered veterans are special disabled veterans, recently separated veterans, Vietnam era veterans, or any other veterans who served on active duty during a war or in a campaign or expedition for which a campaign badge has been authorized) in any of its programs or activities. University policy is intended to be consistent with the provisions of applicable State and Federal laws.

Inquiries regarding the University's nondiscrimination policies may be directed to the Affirmative Action/Staff Personnel Services Director, University of California, Agriculture and Natural Resources, 1111 Franklin Street, $6^{\text {th }}$ Floor, Oakland, CA 94607-5201, (510) 987-0096. For information about ordering this publication, telephone 1-800-994-8849.

\section{UC}

This publication has been anonymously peer reviewed for technical accuracy by University of California scientists and other qualified professionals. This review process was managed by the ANR Associate Editor for Natural Resources.

web-1/10-SB/RW 
In 2004, University of California Cooperative Extension, with support from the Rivers and Mountains Conservancy and in collaboration with the English as a Second Language faculty and students at East Los Angeles College, began to develop a curriculum for English language acquisition based on local environmental issues. The driving principle behind this was that awareness, understanding, and stewardship of one's environment was an important element of membership in a community, and that this understanding would improve both our environment and our communities. Immigrants to the United States should be aware that they have the right to a clean, healthy environment, that there are avenues they can take individually to influence the quality of their environment, and that the decisions made by communities and governments affect that environment. We hope to have two major impacts: to increase the diversity of voices influencing environmental quality and health, and to empower new immigrants with the ability to wield this influence.

In much of California, water is the key limiting factor for ecosystems as well as human societies and economies. Hence, we chose water and the watershed as unifying themes for this unit of our curriculum. While "environment" is a somewhat vague concept, the watershed has real, physical meaning. Physically, a watershed is a land area within which any drop of rain that falls will end up in a single river or lake, but it is also more than that, encompassing everything that can happen to that drop of water along the way. It links the plants, animals, people, businesses, and everything else that use water. It is affected by geology, ecology, economy, society, politics, and culture within and outside that specific geographic area.

When first embarking on this project, we choose to follow the mainstream ESL education community in embracing the concept of English immersion. Hence, all materials are provided in English and can be used in a classroom where a wide diversity of national origins are represented, as was the case with the mix of students with Latin American and Asian origins represented at East Los Angeles College.

This curriculum is not intended to provide a broad overview of all environmental issues, but rather to focus on some that would be relevant to the majority of recent immigrants living in arid urban situations. At the same time, it is not intended to act as the primary ESL curriculum, but as supplemental material. During development, we used it closely with one of the major ESL texts used in California, Stand Out, but our pilot experiences have shown that it is a good complement to other texts as well.

The curriculum is also designed to support the major system of ESL evaluation used in California and throughout the United States, CASAS. The CASAS competencies and EL Civics objectives met by the lessons are outlined in a table on page 2 . An assessment tool for one of the CASAS Civics Education Objective for accessing community services information is provided on page 60 . Lessons addressing listening, speaking, reading, and writing are outlined in the table as well.

We hope that ESL instructors and students will find this a useful tool to expand English language communication skills, meet assessment requirements, learn about environmental issues, and encourage and provide the skills for greater civic engagement in the management of California's natural resources.

\section{Sabrina Drill}

Natural Resources Advisor, University of California Cooperative Extension (323) 260-3404

sldrill@ucdavis.edu 
Overview

CASAS Competencies/EL Civics Objectives/Language Objectives . . . 2

\section{LESSON 1: WATER, WATER EVERYWHERE}

Objectives, Preparation, Materials, Key Vocabulary,

Warm-Up, Introduction . . . . . . . . . . . . ...3

Presentation 1: Water Proverbs ............. . . 3

Water Proverbs Cutouts. . . . . . . . . . . . . 4

Presentation 2: Synonyms and Definitions . . . . . . 6

Presentation 3: Body of Water. . . . . . . . . . . 7

Presentation 4: Water Poems. . . . . . . . . . . . . 7

Assessment. . . . . . . . . . . . . . . . . 9

Wrap-Up ..................... . . 9

Expansion. . . . . . . . . . . . . . . . . . 9

\section{LESSON 2: WATER CONSERVATION}

Objectives, Preparation, Materials, Key Vocabulary,

Warm-Up, Introduction . . . . . . . . . . . . . . 11

Presentation 1: The Water Planet . . . . . . . . . . . 11

The Water Planet Figures A-D . . . . . . . . . . . . . . 12

Presentation 2: How Much Water Do We Use? . . . . . . . 13

Presentation 3: Water Tips, Rebates, and Programs. . . . . 14

Assessment. . . . . . . . . . . . . . . 16

Wrap-Up ....................... . . 16

Expansion. ...................... 16

\section{LESSON 3: WATER IN YOUR COMMUNITY}

Objectives, Preparation, Materials, Key Vocabulary,

Warm-Up, Introduction . . . . . . . . . . . . . . 18

Presentation 1: Map Features . . . . . . . . . . . . 19

Presentation 2: Changing Rivers. . . . . . . . . . . . . 19

Presentation 3: The Los Angeles River . . . . . . . . . 20

The Los Angeles River: Reading Passages. . . . . . . . . 22

Assessment. . . . . . . . . . . . . . . . . . . . . 27

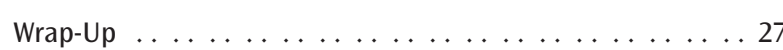

Expansion. ...................... 28

\section{LESSON 4: WATERSHEDS}

Objectives, Preparation, Materials, Key Vocabulary,

Warm-Up, Introduction . . . . . . . . . . . . . . . 29

Presentation 1: Where Does the Water Flow? . . . . . . . . 29

Presentation 2: What Are Watersheds? . . . . . . . . . . . 30

Presentation 3: Two Watersheds. . . . . . . . . . . . 31

Assessment. . . . . . . . . . . . . . . . . . . 32

Wrap-up. . . . . . . . . . . . . . . 32

Expansion. .................... 34

\section{LESSON 5: REDUCING WATER POLLUTION}

Objectives, Preparation, Materials, Key Vocabulary,

Warm-Up, Introduction . . . . . . . . . . . . . . . . . 35

Presentation 1: Two Causes of Water Pollution . . . . . . 36

Presentation 1B: Scanning . . . . . . . . . . . . . . 37

Presentation 2: Sewers and Storm Drains . . . . . . . . . 37

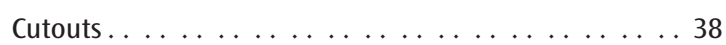

Presentation 3: Los Angeles Storm Drains . . . . . . . . . 39

Presentation 4: Reducing Pollution. . . . . . . . . 40

Assessment. . . . . . . . . . . . . . . . . . . . . . 42

Wrap-Up ...................... . . 42

Expansion. ..................... . . 42

Student Workbook . . . . . . . . . . . . . . . . 43

CASAS 23 Assessment. . . . . . . . . . . . . . . . 60 
Student Workbook

Teacher's edition is listed first, student workbook is listed second (43/1

\section{LESSON 1: WATER, WATER EVERYWHERE}

Objectives. . . . . . . . . . . . . . . . . . . . . . .43/1

Exercise 1: Water Proverbs . . . . . . . . . . . . . . . . .43/1

Exercise 2: Synonyms and Definitions . . . . . . . . . . 43/1

Exercise 3: Body of Water . . . . . . . . . . . . . . 43/2

Exercise 4: Water Poems . . . . . . . . . . . . . . . 44/3

Exercise 5: Make Your Own Poem. . . . . . . . . . . . . . . . .44/4

Assessment. . . . . . . . . . . . . . . . . . . . . . . . . . 44/4

Expansion. . . . . . . . . . . . . . . . . . . . .44/4

\section{LESSON 2: WATER CONSERVATION}

objectives. . . . . . . . . . . . . . . . . . . .45/6

Exercise 1: Key Vocabulary . . . . . . . . . . . . . . . 45/6

Exercise 2: The Water Planet . . . . . . . . . . . . . . .45/6

Exercise 3: How Much Water Do We Use? . . . . . . . . . . . 45/6

Exercise 4: Water Tips, Rebates, and Programs . . . . . . . 46/7

Assessment. . . . . . . . . . . . . . . . . . . . . . 47/9

Expansion. . . . . . . . . . . . . . . . . . . . . . . . .47/9

\section{LESSON 3: WATER IN YOUR COMMUNITY}

Objectives. . . . . . . . . . . . . . . . . 47/10

Exercise 1: Key Vocabulary. . . . . . . . . . . . . . . 47/10

Exercise 2: Map Features . . . . . . . . . . . . . . . . . 47/10

Exercise 3: Changing Rivers. . . . . . . . . . . . . . . 48/11

Exercise 4: The Los Angeles River: Vocabulary in Context . . 48/12

Exercise 5: The Los Angeles River:

Comprehension Questions . . . . . . . . . . . . . . . 49/13

Exercise 6: The Los Angeles River: Reading Passages . . . . 50/15

Assessment. . . . . . . . . . . . . . . . . . . . 51/18

Expansion. . . . . . . . . . . . . . . . . . . 52/19

\section{LESSON 4: WATERSHEDS}

Objectives. . . . . . . . . . . . . . . . . . . 52/20

Exercise 1. Key Vocabulary . . . . . . . . . . . . . . . . 52/20

Exercise 2: Where Does the Water Flow?. . . . . . . . . . 52/20

Exercise 3: What Are Watersheds?. . . . . . . . . . . . . 52/20

Exercise 4: Two Watersheds . . . . . . . . . . . . . . . 53/21

Exercise 5: Protecting Our Watersheds . . . . . . . . . . . 54/23

Assessment. . . . . . . . . . . . . . . . . . . . 54/23

Expansion. . . . . . . . . . . . . . . . . . . . . . 54/24

\section{LESSON 5: REDUCING WATER POLLUTION}

Objectives. . . . . . . . . . . . . . . . . . . . 55/25

Exercise 1. Key Vocabulary . . . . . . . . . . . . . . . . 55/25

Exercise 2: Two Causes of Water Pollution. . . . . . . . . . 55/25

Exercise 3: Two Causes of Water Pollution: Scanning. . . . 55/26

Exercise 4: Sewers and Storm Drains. . . . . . . . . 55/26

Exercise 5: Is This a Sewer or a Storm Drain? . . . . . . . . 56/27

Exercise 6: Los Angeles Storm Drains. . . . . . . . . . . 56/27

Exercise 7: Reducing Pollution. . . . . . . . . . . . . . 56/28

Exercise 8: Who Can You Call For Help? . . . . . . . . . . . 57/30

Assessment. . . . . . . . . . . . . . . . . . . . . . . . . . 57/30

Expansion. . . . . . . . . . . . . . . . . . . . . . . 58/31

GLOSSARY.

$59 / 32$ 
Water drives life on planet Earth, and clean, safe water is one of the most basic human needs. The history of California, and Southern California in particular, was in large part determined by the need for water. In this unit, you and your classes will learn about and discuss the role water plays in life in California and in the lives of your students in their home countries. Most of our water comes from rivers, and you will learn about how and why we have changed our local rivers and their watersheds. Your classes will also practice reading maps, both to learn more about the natural geography of Los Angeles and gain important skills that can improve their lives in this country.

Each lesson includes objectives for the students, preparation suggestions, a list of materials needed, and key vocabulary covered in the lesson. Warm-up and introductory exercises help build student interest and review the concepts they already know. For each presentation in the lesson, there are practice exercises and an evaluation. The end of each lesson includes assessment questions and expansion exercises that encourage students to transfer the acquired concepts into their lives outside of the classroom.

At the end of the unit, there are a set of suggested student projects, and an assessment tool based on this material that you can use to evaluate a CASAS EL Civics Objective. Finally, there is a glossary of important vocabulary used throughout the unit.

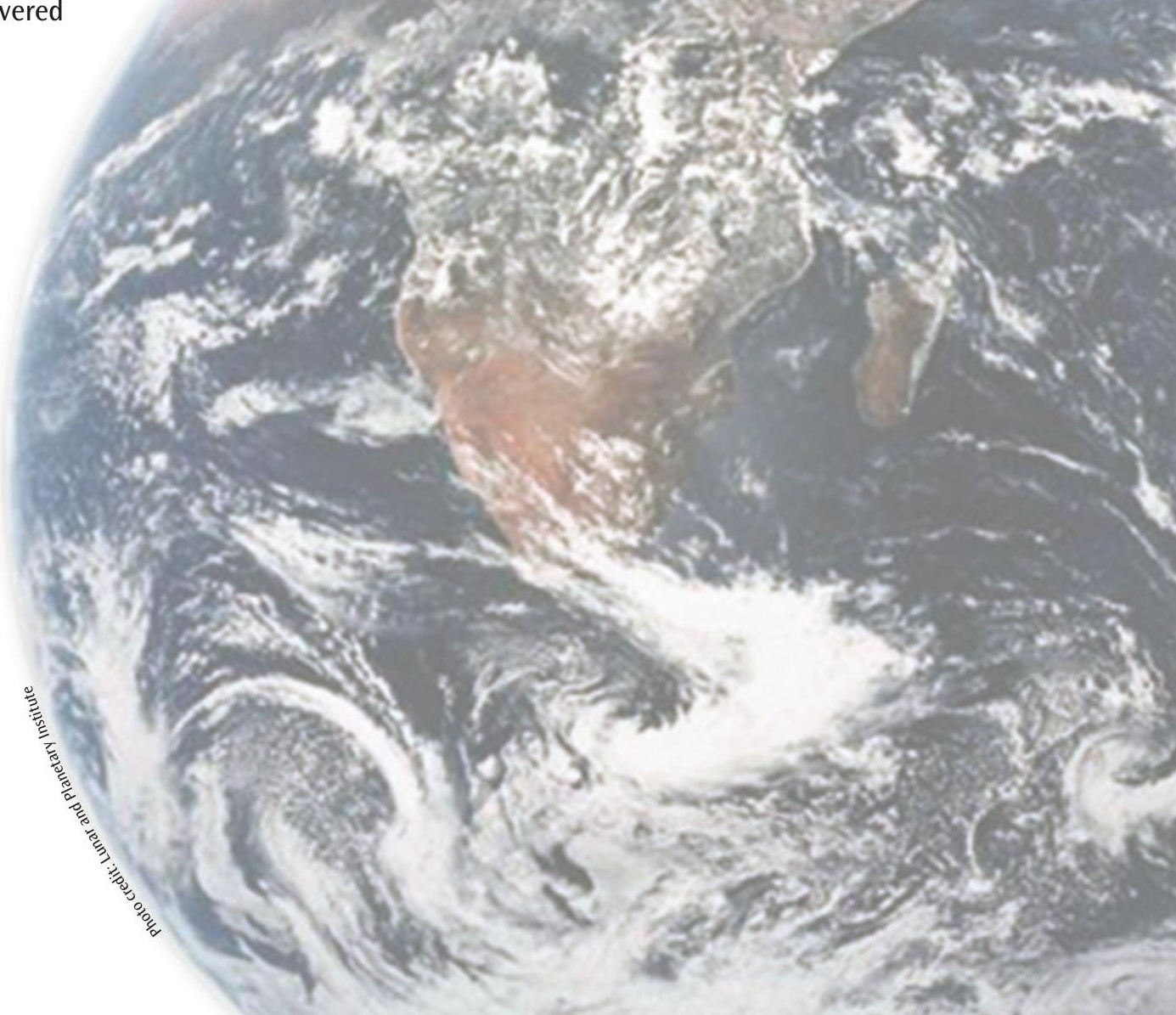




\section{CASAS COMPETENCIES/EL CIVICS OBJECTIVES/LANGUAGE OBJECTIVES}

\begin{tabular}{|c|c|c|c|c|c|c|c|c|c|}
\hline \multirow[t]{2}{*}{ LESSON } & \multirow{2}{*}{$\begin{array}{c}\text { EL CIVICS } \\
\begin{array}{c}\text { Competency/ } \\
\text { language objective }\end{array}\end{array}$} & \multicolumn{2}{|c|}{ LISTENING } & \multicolumn{2}{|c|}{ SPEAKING } & \multicolumn{2}{|c|}{ READING } & \multicolumn{2}{|c|}{ WRITING } \\
\hline & & Presentation & Page & Presentation & Page & Presentation & Page & Presentation & Page \\
\hline $\begin{array}{l}\text { 1: } \\
\text { Water, Water } \\
\text { Everywhere }\end{array}$ & $\begin{array}{l}8.1 \\
11.8 \\
13.5 \\
22.1 \\
43.1-8\end{array}$ & $\begin{array}{l}1 \\
2 \\
2 \text { Expansion }\end{array}$ & $\begin{array}{l}\text { p. } 3 \\
\text { p. } 6 \\
\text { p. } 9\end{array}$ & $\begin{array}{l}1 \\
1 \text { Expansion }\end{array}$ & $\begin{array}{l}\text { p. } 3 \\
\text { p. } 9\end{array}$ & $\begin{array}{l}1 \\
2 \\
3\end{array}$ & $\begin{array}{l}\text { p. } 3 \\
\text { p. } 6 \\
\text { p. } 7\end{array}$ & $\begin{array}{l}2 \\
3 \\
3 \text { Expansion }\end{array}$ & $\begin{array}{l}\text { p. } 6 \\
\text { p. } 7 \\
\text { p. } 9\end{array}$ \\
\hline $\begin{array}{l}2: \\
\text { Water } \\
\text { Conservation }\end{array}$ & $\begin{array}{l}8.2 \\
8.3 \\
8.9 \\
11.13 \\
13.5 \\
25.3 \\
43.1-8\end{array}$ & 1 & p. 11 & 1 Expansion & p. 16 & $\begin{array}{l}2 \\
3\end{array}$ & $\begin{array}{l}\text { p. } 13 \\
\text { p. } 14\end{array}$ & $\begin{array}{l}2 \\
2 \text { Expansion }\end{array}$ & $\begin{array}{l}\text { p. } 13 \\
\text { p. } 16\end{array}$ \\
\hline $\begin{array}{l}\text { 3: } \\
\text { Water in Your } \\
\text { Community }\end{array}$ & $\begin{array}{l}8.2 \\
13.2 \\
22.7 \\
25.3 \\
43.1-8\end{array}$ & $\begin{array}{l}3 \\
3 \text { Expansion }\end{array}$ & $\begin{array}{l}\text { p. } 20 \\
\text { p. } 28\end{array}$ & $\begin{array}{l}2 \\
3 \\
3 \text { Expansion }\end{array}$ & $\begin{array}{l}\text { p. } 19 \\
\text { p. } 20 \\
\text { p. } 28\end{array}$ & $\begin{array}{l}1 \\
3\end{array}$ & $\begin{array}{l}\text { p. } 19 \\
\text { p. } 20\end{array}$ & $\begin{array}{l}3 \\
3 \text { Expansion }\end{array}$ & $\begin{array}{l}\text { p. } 20 \\
\text { p. } 28\end{array}$ \\
\hline $\begin{array}{l}\text { 4: } \\
\text { Watersheds }\end{array}$ & $\begin{array}{l}8.2 \\
8.9 \\
11.13 \\
13.5 \\
23.1 \\
43.1-8\end{array}$ & $\begin{array}{l}1 \\
2 \\
3\end{array}$ & $\begin{array}{l}\text { p. } 29 \\
\text { p. } 30 \\
\text { p. } 31\end{array}$ & $\begin{array}{l}1 \\
3\end{array}$ & $\begin{array}{l}\text { p. } 29 \\
\text { p. } 31\end{array}$ & 2 & p. 30 & $\begin{array}{l}2 \\
2 \text { Expansion }\end{array}$ & $\begin{array}{l}\text { p. } 30 \\
\text { p. } 34\end{array}$ \\
\hline $\begin{array}{l}\text { 5: } \\
\text { Reducing } \\
\text { Water Pollution }\end{array}$ & $\begin{array}{l}8.2 \\
13.5 \\
43.1-8\end{array}$ & $\begin{array}{l}1 \\
2 \\
3\end{array}$ & $\begin{array}{l}\text { p. } 36 \\
\text { p. } 37 \\
\text { p. } 39\end{array}$ & 2 & p. 37 & $\begin{array}{l}1 \\
2 \\
3 \\
4\end{array}$ & $\begin{array}{l}\text { p. } 36 \\
\text { p. } 37 \\
\text { p. } 39 \\
\text { p. } 40\end{array}$ & $\begin{array}{l}1 \\
3 \\
4 \\
4 \text { Expansion }\end{array}$ & $\begin{array}{l}\text { p. } 36 \\
\text { p. } 39 \\
\text { p. } 40 \\
\text { p. } 42\end{array}$ \\
\hline
\end{tabular}




\section{Objectives}

To acquire and share words pertaining

to water

To share and

analyze proverbs

that use

water words

To define

"synonym"

$$
\begin{aligned}
& \text { To use a } \\
& \text { thesaurus } \\
& \text { to find synonyms }
\end{aligned}
$$

\section{PREPARATION}

This lesson is designed to get students thinking more about water. Familiarize yourself with the water vocabulary in the lesson and add any words that may be relevant to your locale (e.g., are there wetlands nearby?). Make copies of the "Water Proverbs" in Presentation 1 (one page is enough for 32 students) and cut each proverb into a strip, and then cut the strip in half.

\section{MATERIALS}

Proverb strips cut in half; pictures and/or tangible examples of waterrelated words to generate interest and comprehension; a thesaurus.

\section{KEY VOCABULARY}

proverb

body of water

thesaurus

synonym

vital

\section{WARM-UP}

(5 minutes)

As students enter the classroom, give each one half of a proverb. Be sure their matching strip is handed out as well. Tell them that they have the beginning or ending of a proverb (write "proverb" on the board). Tell them that every language has proverbs and explain that proverbs are expressions that give advice or opinions about life.

\section{INTRODUCTION}

\section{(5 minutes)}

Remind students that water is something that connects everyone on earth, and therefore every language and culture has proverbs that use water to talk about some aspect of life (you may want to discuss what a metaphor is here). Explain that in this lesson they will share and analyze water proverbs, learn new water words, and learn how to increase their vocabulary.

\section{PRESENTATION 1: WATER PROVERBS}

(5-10 minutes)

Have students walk around the classroom, using English to find the match for their half of their proverb. Once they have found the person who holds it, they should sit together.

\section{Practice 1}

(10-15 minutes)

Pairs should try to guess the meaning of the proverb and discuss whether people say something similar in their first language. Have them teach each other the proverb in their own language, if it exists. 


\section{Water, Water Everywhere}

WATER PROVERBS

Thousands have lived without love

He who prays for rain

Water is

I feel like a fish

It is raining

Water, water everywhere

You can lead a horse to water

Water in the mouth before eating not one without water.

prays for mud.

the mother of tea.

out of water.

cats and dogs.

and not a drop to drink.

but you cannot make him drink.

water in the eyes when the bill comes. 


\section{Water, Water Everywhere}

continued

This is just the tip

of the iceberg.

When it rains

it pours.

without a paddle.

Up the creek

come again some other day.

Rain, rain, go away

Saving it for

a rainy day.

Keep your head

above water.

I wash my hands

of the whole thing.

You will not miss the water

until the well runs dry. 


\section{Evaluation 1}

(15-30 minutes)

Pairs present their proverbs to the class, teaching the meaning and teaching the proverb in their first language if it exists. Have students complete Exercise 1 in their workbooks.

\section{PRESENTATION 2: SYNONYMS}

(10 minutes)

1. Write "beautiful" on the board and ask whether they know of another word that has a similar meaning (e.g., "pretty"). Say that "pretty" and "beautiful" are synonyms. Write "synonym" on the board and elicit the meaning. Ask them for more examples (e.g., tired-sleepy; happy-joyful, etc.).

2. Show students a thesaurus and explain that it is a good resource for finding synonyms. Explain that using a thesaurus will help them increase their vocabulary, because every time they look for one word in the thesaurus, they will learn at least one new word that has a similar meaning.

3. Ask a student to look in the thesaurus for synonyms of "vital." After generating a list of synonyms, ask for an example of something that is vital. Elicit that "water is vital" and explain that throughout these lessons they will learn and share many things about water.

4. Next, ask if there is any other information about vital in the thesaurus (elicit "antonym"). Explain that an antonym is the opposite of a word. Ask for examples of antonyms for the sample words you gave above.

5. Point out that some of the sample words do not have synonyms, in which case they can check for definitions in a dictionary.

\section{Practice 2}

(30-40 minutes)

Tell students they will learn many new words throughout this unit. Explain that by learning some of the words now, it will be easier for them to understand the future lessons. Have students find synonyms and/or definitions for the words in their workbooks (Exercise 2). (Note: This can be done as homework to save class time. Answers will vary.)

\section{Exercise 2: Vocabulary List}

proverb: A short statement that expresses a basic truth. synonym: A word with a similar meaning. antonym: A word with an opposite meaning. thesaurus: A book containing synonyms and antonyms. saltwater: Relating to water from the sea or ocean. freshwater: Water that does not contain salt.

lake: A body of freshwater.

river: A large body of fresh, moving water.

stream: A body of moving water.

creek: A small body of moving water.

lagoon: A body of shallow water connected to a larger body of

water like an ocean, lake, or river.

ocean: A very large body of salt water that covers most of the earth and can be divided into five parts (Atlantic, Pacific, Indian, Southern, Arctic).

sea: A large body of water totally or partially enclosed by land. 
pond: A small lake.

spring $(n)$ : A body of water that flows from underground.

brook: A small stream.

marsh: Wet land.

flood (n): An overflowing of water on dry land; water out of its

normal boundaries.

shed $(v)$ : To release water.

drain (v): To flow off gradually.

soak: To make something completely wet.

watershed: the area where water travels from one place to another.

(Note: Students will find more than one definition for this word and

should be able to tell from the context of this lesson which is most

appropriate.)

vital: Necessary.

\section{Evaluation 2: Body of Water}

(15-20 minutes)

Students compare their definitions and synonyms and then check

as a class.

\section{PRESENTATION 3: BODY OF WATER}

\section{(5 minutes)}

Write "body of water" on the board and say that "ocean" and "river" are examples. Ask if they can guess the definition of the phrase "body of water." Then have students look up "body" in the dictionary and see if they can figure out how to define "body of water" and discuss it with the class. Have them write the definition at the top of Exercise 3 in their workbooks.

\section{Practice 3}

(15-20 minutes)

Have students complete Exercise 3 in their workbooks.

\section{Evaluation 3}

(5 minutes)

Check the answers as a class.

\section{PRESENTATION 4: WATER POEMS}

\section{(5 minutes)}

Tell students that they will now read three poems written by students about water. Ask them to read the questions in Exercise 4 before reading the poems.

1. Who or what is speaking in "Seasons of Water"?

2. In "Water," what are the antonyms for "steady" and "old"?

3. Who or what is speaking in "Untitled"? Is it a different speaker from "Seasons of Water"?

4. Make a list of the words in the poems that are related to water. 


\section{Seasons of Water}

Winter

I am the soft, white snow you play in.

I am the steam that rises from your hot cocoa on a cold day. Spring

I am the gentle shower you dance in.

I am the glistening dewdrops on a crisp, clear morning.

Summer

I am the refreshing mountain pool you splash in.

I am the splat of a water balloon on your back.

Fall

I am the icy cold rain that keeps you inside for recess.

I am the pitter, patter that hits the window when you are curled up beside the fire.

I am the water of your life

Katy Wilson, Age 9

Collegedale, Tennessee

National Finalist

2006 River of Words Contest

(c) River of Words

\section{Untitled}

I flow from the mighty mountain down through the magic of moss, mist and forest. I flow through mighty desert, fire and rain through cool shade and burning sun.

Iflow through beautiful places, ugly places night and day, under suns and moons.

I flow through disaster and magnificent glory precious moments and hated past.

I flow through life and study it.

I protect life along with taking it.

I see all and yet I am only a river, strong and free.

Lauren Anderson, Age 11

Watsonville, California

National Finalist,

2006 River of Words Contest

(c) River of Words

\section{Water}

Water is as steady as thoughts as unstable as a child's first steps as old as time as fresh as life as mysterious as dreams

Amanda Ditmore, Age 9 Berkeley, California

National Finalist 2006 River of Words Contest

(C) River of Words 


\section{Practice 4}

(30 minutes)

Ask students to complete Exercise 4.

\section{Evaluation 4}

(10 minutes)

Discuss students' workbook answers as a class. Then have students complete Exercise 5 as homework to share with the class or a partner in the following class.

\section{ASSESSMENT}

At the conclusion of the lesson, students should be able to answer these questions in English (the assessment in their workbook):

\section{What new water words did you learn?}

2. What can you find in a thesaurus?

3. Name three synonyms for "vital."

4. Name three things that are vital to human life.

\section{WRAP-UP}

Tell students that now they have learned many words that are related to water and have a new tool to help them expand their English vocabulary. Explain that next they will learn about the availability of freshwater and will discuss the importance of saving it. Also, they will share and learn new ways to save water.

\section{EXPANSION (written to the student)}

\section{Writing}

1. "My Favorite Body of Water"

Close your eyes and think about your favorite river, ocean, or other body of water for about 5 minutes (if you can't think of one, create the ideal one). When you open your eyes, write down everything you remember about that place. Describe it so well that if someone reads what you wrote, they will feel like they are in front of that body of water. If you prefer, you can write it in the form of a poem. When you are finished, read it to your classmates.

\section{Water in the Media}

While studying all about water, pay attention to television and radio programs or newspaper articles that talk about water. Whenever you hear or read anything about water, write it down and tell the teacher and class all about it. For example, while writing this curriculum, there was a big story in the news about cleaning up the Los Angeles River, sponsored by Friends of the Los Angeles River. This is something that you can share with the class, your teachers and friends.

\section{Family Activity}

1. Water Use

Have everyone in your family observe his or her own water use. How many times in one day do you (and your family members) turn on the faucet, drink water, or wash with water? Try to use as much English at home as possible to complete the exercise.

2. River of Words

River of Words (ROW) is an educational nonprofit organization based in Berkeley, California, that promotes cultural and environmental literacy through the arts and cultural exchange. 
ROW conducts an annual international poetry and art contest for youth, in affiliation with the Library of Congress Center for the Book. Through its teacher workshops, curriculum materials, exhibitions, and publications, ROW encourages students around the world to explore their own communities and imaginations-weaving in natural and cultural history-and then to synthesize what they've learned and observed into line and verse.

River of Words was cofounded in 1995 by United States Poet Laureate (1995-97) Robert Hass and writer Pamela Michael. In 2003 River of Words opened one of the only art galleries in the world devoted exclusively to the work of children, called "Young at Art."

For information or to order art prints, calendars, ROW art and poetry books, the 270-page Educator's Guide, or other curriculum materials write to:

River of Words, PO Box 4000-J, Berkeley, CA 94704;

tel: 510-548-POEM (7636); Web site, www.riverofwords.org.
3. Search the Web

Many Web sites have poems and proverbs that include water words. Teach your children (or other young people you know) how to search the World Wide Web (or maybe they can teach YOU!). A good place to begin is www.google.com and type in "poems or proverbs about water."

4. Web Sites about Water

There are many other Web sites dedicated to teaching more about water. Three more to investigate are given below. How many more can you find?

- World Water Day, http://www.worldwaterday.org

- University of California World Water Resources Archives, http:// www.lib.berkeley.edu/WRCA

- Water Education Foundation, http://www.watereducation.org

\section{Grammar}

Practice making yes-no questions and short answers by interviewing people about the water in their countries. 


\section{Objectives}

To compare the availability of

freshwater on the earth to the need

for freshwater

$$
\begin{aligned}
& \text { To define } \\
& \text { "conservation" } \\
& \text { To identify and } \\
& \text { share ways to } \\
& \text { conserve water }
\end{aligned}
$$

\section{PREPARATION}

Familiarize yourself with Presentation 1 prior to the lesson so that the steps run smoothly. You may need more than the estimated time as well as some materials not readily available in the classroom (see suggestions below).

\section{MATERIALS}

Presentation 1: Something to divide, such as apples, M\&Ms, pizza, or wedges of paper; a globe or a picture of earth from outer space (e.g., from Google Earth, http://earth.google.com); a thesaurus; and, for Presentation 2, a gallon jug.

\section{KEY VOCABULARY}

drinkable

saltwater

freshwater

gallon

conserve

average

faucet

leak

leaky

\section{WARM-UP}

(5 minutes)

Ask for volunteers to read their "My Favorite Body of Water" writing from Lesson 1. Have students complete Exercise 1, giving as many definitions or synonyms as they can remember from Lesson 1 .

\section{INTRODUCTION}

(5 minutes)

Tell students that in this lesson they will compare how much water is on the earth with how much there is for humans to use, and that they will share and learn new ideas for saving water.

\section{PRESENTATION 1: THE WATER PLANET}

\section{(15-30 minutes)}

This presentation is described below as a teacher-directed listening lesson. You can also use it as a "following instructions" exercise in which students draw and make the divisions as you go through the steps. Or, you might make it more tactile by using (or having the students use) the materials suggested above.

1. Tell students that some people call Earth the "Water Planet." Ask them why they think that is. (It is because so much of the planet is covered by water-use a globe or map to emphasize.).

2. Draw a large circle on the board and tell students that the circle represents the planet Earth (see figs. A-D). 
3. Now divide the Earth into four equal sections (fig. A). Explain that the sections represent all land and water on the planet.

4. Ask students how many sections they think represent the water on the Earth. Shade in three sections (fig. A) and tell the students that these sections represent the water on the earth.

5. Erase the remaining section that represents the land (fig. B).

6. Explain that most of the water in the remaining sections is salt water (from the oceans), which is undrinkable (you can't drink it).

7. On the side, draw what is roughly less than half of one of the sections (fig. C) and explain that only this section of the water is freshwater. Erase the circle representing salt water.

8. Ask students if they think this is enough water for everyone (answers may vary). Now divide this final section roughly into thirds (fig. D) and say that two of the sections are frozen freshwater-like the ice at the North and South Poles-which is also undrinkable. Erase the two thirds that represent frozen freshwater.

9. Explain that this final small remaining section of liquid freshwater represents all the water that can be available to us. (Note: We use the words "can be" because some of that remaining water is polluted and therefore also undrinkable. Pollution is explored in depth in a future lesson.)

Figures A-D. Availability of water on Earth.

A.

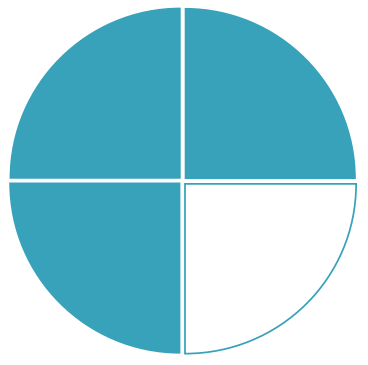

saltwater

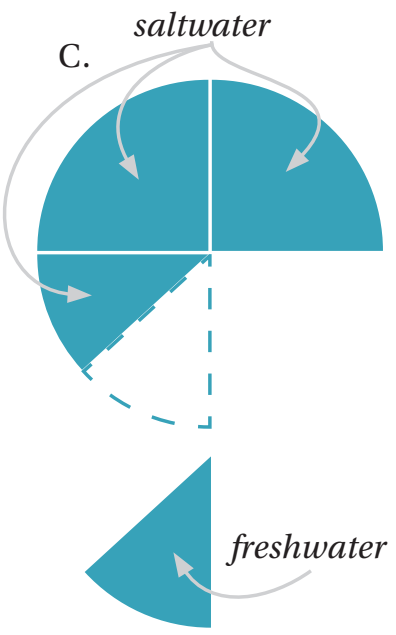

B.

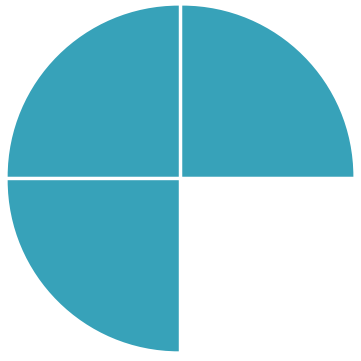

D.

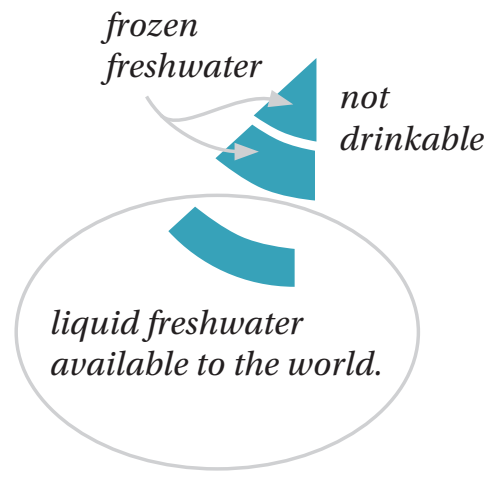




\section{Evaluation 1}

(5-10 minutes)

Have students discuss in pairs whether they think the amount of freshwater available on earth affects their daily lives and what it means for the future, and have them brainstorm some solutions to our lack of freshwater. Have students complete Exercise 2 in their workbooks. Check the answers as a class. (The correct answer in Exercise 2 is "Water, water everywhere and not a drop to drink").

\section{PRESENTATION 2: HOW MUCH WATER DO WE USE?}

\section{(15-20 minutes)}

Tell the students that they are going to read about how much water people use doing certain activities. Show them a gallon container for reference.

\section{Practice 2}

(10 minutes)

Have students complete Exercise 3 (below) in their workbooks.

\section{ACTIVITY}

\section{Typical number of gallons used}

$\underline{\mathrm{H}}$ Taking a bath or shower

D Watering the lawn and yard

F Washing the dishes by machine or hand

A Washing clothes

E Washing the car

」 Brushing your teeth

$\underline{G}$ Cooking

B Drinking

C Flushing the toilet (once)

1 Leaking toilet (per day)

Source: Water Education Foundation.

\section{Evaluation 2}

(5-10 minutes)

Correct Exercise 3.
A. $35-50$ gallons

B. 1/2 gallon

C. 4-7 gallons

D. 180 gallons

E. 50 gallons

F. 8-13 gallons

G. 5-10 gallons

H. 9-12 gallons

I. 60 gallons

J. 2-5 gallons 


\section{PRESENTATION 3:}

\section{WATER TIPS, REBATES, AND PROGRAMS}

(15-20 minutes)

Write "conserve" on the board and ask a student to find its synonym in their (or your) thesaurus and share any synonyms with the class. Explain that "conservation" is the noun form of the verb "conserve." Tell the students that water conservation is an important way to make sure that their children, grandchildren, and great grandchildren have enough water to survive.

\section{Practice $3 A$}

(20-30 minutes)

Tell students that they are going to read about how to be "water-wise," or smart about water use. Say that the information will give them ideas about how to conserve water. Have them read the questions (Exercise 4) before they read the information so they can have ideas to focus on while they read.
Questions:

1. Referring to the tips in Exercise 4, name three things you can do in the bathroom to save water.

2. Name three things you can do in the kitchen to save water.

3. According to the tips, when is the best time to do laundry?

4. Which saves more water: washing your car yourself or taking your car to a car wash? Why?

5. How can you get a rebate for the following amounts?

$\$ 100.00$

$\$ 150.00$

$\$ 175.00$

$\$ 75.00$

6. Did you learn new ways to conserve water by reading these tips? Why or why not?

7. List at least three other ways you can think of (or have already used) to conserve water.

\section{Practice 3B (Reading)}

(30-40 minutes)

Have students read the information independently. 


\section{WATER-WISE TIPS, REBATES, AND PROGRAMS FOR EAST LOS ANGELES}

\section{Water-Wise Tips}

(0) Take shorter showers; use less water in your baths.

(2) Don't leave the faucet on when you brush your teeth or your hair.

(0) Don't leave the water on when you wash dishes. Instead, fill the sink or wash tub to wash and rinse dishes.

(2) When you are waiting for water to heat up, collect the cold water and use it for plants.

(2) Check all faucets for leaks and replace any leaky washers.

(2) Is your toilet leaking? Put a drop of food coloring in the tank and don't flush. If the water in the bowl changes color, you have a leak.

(2) When you use the dishwasher or do laundry, wait until you have a full load.

(2) Don't leave the hose running when you wash your car. It is better to take your car to a car wash. They usually use less water and often recycle or throw the dirty water away in the proper place.

(2) Use a broom instead of water to clean up your driveway and walk ways.

(0) Replace your showerheads and toilets with low-flow heads and low-flush models (they might be free!).

\section{Rebates and Programs}

City of Los Angeles Department of Water and Power customers Rebate up to $\$ 100.00$ when you buy an ultra-low-flush toilet. You may even be able to get a free toilet! For more information call (800) 544-4498 or visit the Los Angeles Department of Water and Power (LADP) Web site,www.ladwp.com.

Rebate up to $\$ 150.00$ if you buy a high-efficiency washing machine. Call (800) 203-7380 or visit www.ladwp.com to get an application.

Get free trees! For more information call (800) 473-3652 or visit www.ladwp.com.

\section{City of Monterey Park Water Department:}

Get FREE ultra-low-flush toilets each spring. For more information call (626) 307-1293, or visit the Web site, www.waterprograms.com.

\section{East Los Angeles California Water Service Group}

FREE water-saving plumbing fixtures, like low-flow showerheads, kitchen faucets, and hose nozzles. For more details contact your local office (on your bill) or visit the California Water Service Company Web site, http://www.calwater.com/ WaterSavingPlumbingFixtures.html.

Rebate of $\$ 75.00$ on an ultra-low-flush toilet. Call the Oldtimers Foundation at (877) 732-2830 for more information.

Get a $\$ 175.00$ rebate on a high-efficiency clothes washer through the Central Basin Municipal Water District. Call the Oldtimers Foundation at (877) 732-2830 for more information, or visit http://www.centralbasin.com or www.calwater.com. 


\section{Evaluation 3}

(15 minutes)

Answer the questions in Exercise 3 and discuss them as a class. If students do not live in East Los Angeles, ask them to try to find brochures or information on water conservation in their local area. Suggest that they read their water bill, search the Web, or go to a local garden supply store. Have them share the information they find with the class.

\section{ASSESSMENT}

At the conclusion of the lesson, students should be able to answer these questions in English:

1. How much of the planet consists of water?

2. How much of that water is drinkable?

3. What does "conserve" mean?

4. How did you conserve water in your country?

5. How can you conserve water at home?

\section{WRAP-UP}

Remind students that they have learned many new words related to water and have discovered and shared ways to conserve water. Explain that in the next lesson they will learn more about the bodies of water in your area.

\section{EXPANSION}

\section{Writing}

1. Water Conservation

Write an essay about water conservation. In your introduction, talk about how little water there is available for humans to use on the planet and why it is important to conserve water. In the body, write three paragraphs; each one should present a different option for conserving water. In the conclusion, tell your reader what the future might be like if we don't conserve water.

2. How Much Water Do You Use? For the next 24 hours, observe and write down everything you do that requires water.

\section{Example: 12:35 P.м.: Washed my hands before lunch. 12:40 P.M.: Drank water with my lunch. 1:00 P.M.: Washed the dishes from lunch.}

When you are finished, think about these questions: How many times in 24 hours did you use water? Was it more or less than you expected? Do you think you use more or less water than the other students and teacher? Compare your answers with your classmates and teacher in your next class. Compile the results for the whole class, then research on the Internet to compare your class's average use to water use in the United States or in your native country. 


\section{Water Conservation}

\section{Family Activity}

Do the "Water Planet" exercise with members of your family, using candy, pizza, a tortilla, a dumpling or food that is popular in your country.

\section{Guest Speaker}

Find a professor on your campus who is involved with conservation (possible departments to search for one include earth science, life science, civil engineering, and geology). Prepare interview questions and ask him or her to visit the class. Take notes during the interview, then summarize them in an essay.

\section{Grammar}

Look at Exercise 3 again and observe the use of the gerund as the subject of the sentence. Think of other ways you use water and make a statement about it using the gerund as the subject. 


\section{Objectives}

To get and give directions

\section{To guess}

vocabulary

definitions using

context clues

To compare the

present state of

the Los Angeles

River with

the past

To analyze how

and why the Los

Angeles River

has changed

To list ways to

protect the Los

Angeles River

\section{PREPARATION}

This lesson focuses on the Los Angeles River and is a case study of how a river evolved through the process of urbanization. If you are not in the Los Angeles River watershed, or you would like to learn or teach about a different body of water, feel free to substitute or supplement this lesson with materials and worksheets on a different body of water.

\section{MATERIALS}

AAA maps of Los Angeles and of your local area (one for every three students); globe or world map; map of the United States.

\section{KEY VOCABULARY}

map features

north

south

east

west

flood

native

agriculture

aqueduct

concrete

channel

channelization

desirable

soak

\section{WARM-UP}

\section{(5-10 minutes)}

Have students complete Exercise 1, giving definitions or synonyms they already know (they will learn the others throughout the lesson). Ask what the major rivers are in their countries. In Asia, these might be the Huang He (Yellow River), the Yangtze, or the Mekong; in India, the Ganges; in Latin America, the Tijuana, Rio Grande, Sonora, or Amazon. Ask what some of the major rivers in the United States are (Hudson, Potomac, Missouri, Mississippi, Rio Grande, Colorado, Sacramento, San Joaquin). Have students point these out on a map.

\section{INTRODUCTION}

\section{(5 minutes)}

Tell the students that in this lesson, they will learn about a famous river in Southern California, the Los Angeles River, and how and why the river has changed through the years. Explain that they will also identify features on a map. 


\section{PRESENTATION 1: MAP FEATURES}

(5-10 minutes)

Review the concepts of north, south, east, and west with students. Ask how they can identify streets, rivers, and freeways on maps. Tell them that these are called "map features" in English. Go over the questions that they will be answering in Exercise 2 and answer any questions they have. Distribute the maps and group the students.

\section{Practice 1}

(15-20 minutes)

Have students complete Exercise 2.

1. Find your school on the map.

2. Find the area where you live. What roads could you take to get from your house to school?

3. Looking at the map, can you find some rivers? How do you know they are rivers?

4. What rivers are closest to this school?

5. What communities do these rivers run through? Where do the rivers meet the ocean?

6. Some of our main freeways are built along the rivers. Why do you think some freeways run along the sides of rivers? (The Los Angeles River runs along I-5 and I-710; the San Gabriel River runs along I-10 and I-605. These are flat areas and early settlers needed water. Later, roads were built to link these communities)

\section{Evaluation 1}

(5-10 minutes)

Check answers together.

\section{PRESENTATION 2: CHANGING NAMES}

(5 minutes)

Explain that many street and area names can tell you what an area used to look like. Have them look for these place names on the Los Angeles maps (or maps of your area):

- Spring Street

- La Cienega

- Santa Fe Springs

- Willowbrook

\section{Practice 2}

(10 minutes)

Ask why they think these areas were named "spring" or "brook." Have Spanish speakers, if any, translate cienega ("marsh"). Discuss why so many street and area names in Southern California come from Spanish. Ask if there is still a spring on Spring Street or a marsh on La Cienega (there is not). Discuss what the names tell you about the history of a location. Elicit that these areas were probably wetlands but in many cases no longer are.

\section{Evaluation 2}

\section{(5 minutes)}

Ask students to find more examples and share them with the class. Ask and discuss how streets and areas are named in their countries. 


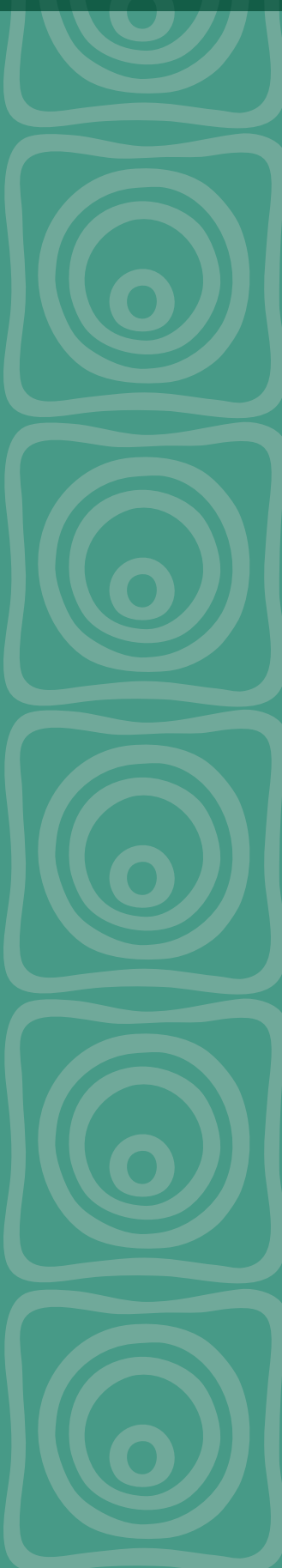

\section{PRESENTATION 3: THE LOS ANGELES RIVER}

(5 minutes)

Tell students that now they will focus on one of the most well-known rivers in Southern California: the Los Angeles River (also known as the LA River). Have students look at the pictures of the Los Angles River (Exercise 3) and ask when they think the pictures were taken. Discuss the similarities and differences between the two pictures. (The first picture was taken in 1900, the second in 2008.) Ask them to guess why so many changes occurred and explain that in the next lessons they will learn more about why.

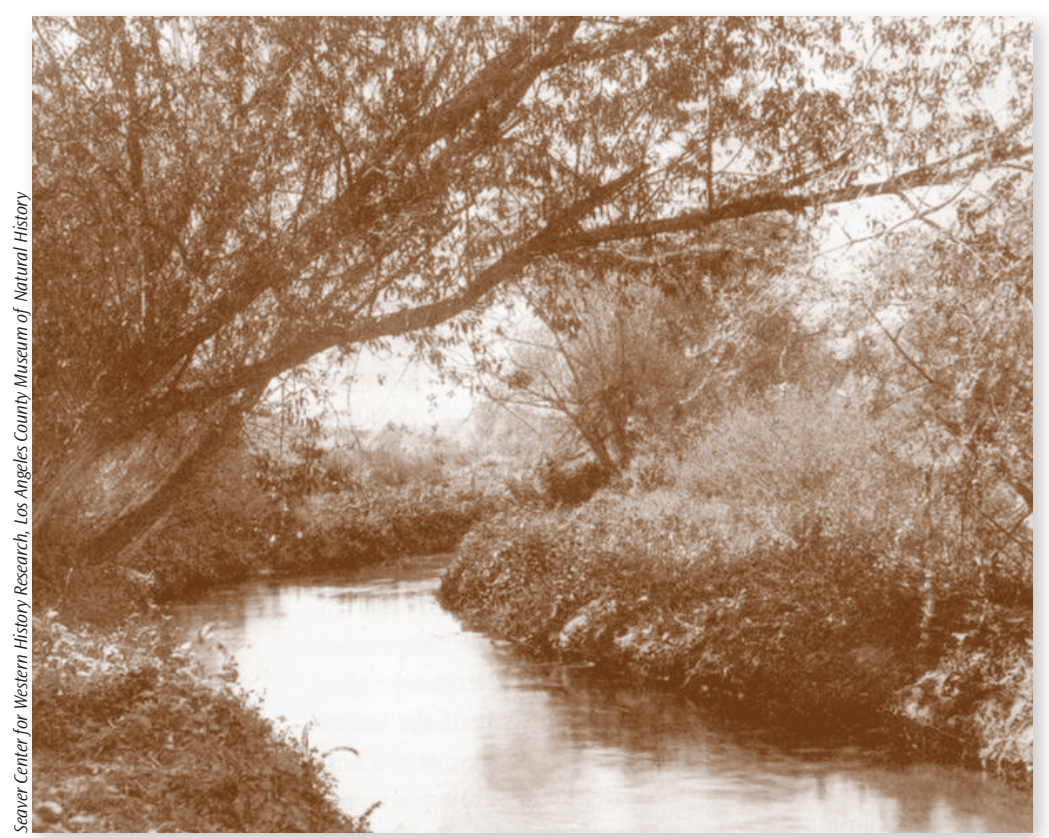

The Los ANgeles River IN THE 1900s.

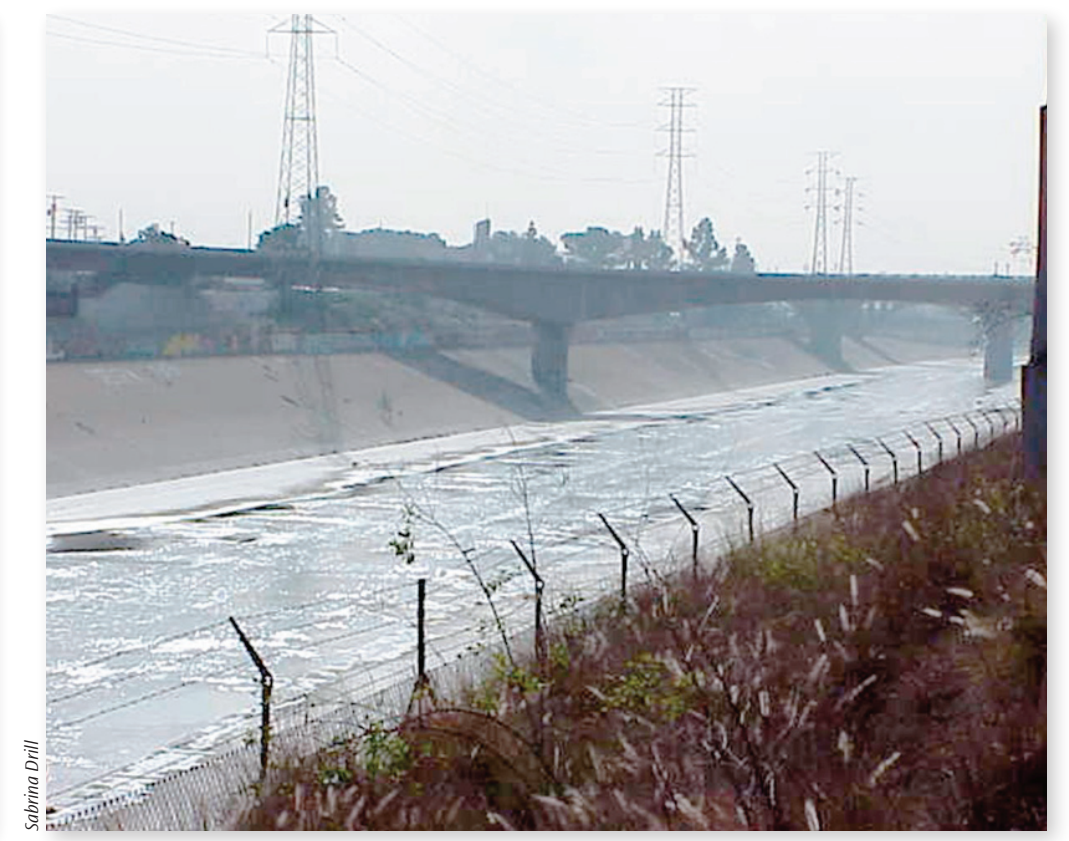

The Los Angeles River in a CONCrete ChanNel NEAR DOWNTOWN, 2008. 


\section{Practice 3: Vocabulary in Context}

(15-20 minutes)

Explain that when reading in English, they might find vocabulary words they don't know and that, in many cases, they can look at other words around the word (called "context") to try to guess the meaning. As an introduction to Exercise 4, go over the example below. The word or phrase to be defined is in bold, as is the correct answer.

Example: When it rained a lot in New Orleans, there was a flood.

A. Too much wind

B. Too much heat

C. Too much snow

D. Too much water

Ask which words give them clues about "flood" (rain, a lot).

\section{Practice 3A}

Ask students to complete Exercise 4 in their workbooks. (Note: the correct answers are shown in bold.)

1. "The Los Angeles River flowed across large areas of Los Angeles."
A. To stop
B. To go from one place to another
C. To throw away
D. To listen

2. "... one of the first Spaniards to visit Los Angeles..."
A. People from Mexico
B. People from Spain
C. People from Los Angeles
D. People from America

3. "The native people of Los Angeles, the Chumash and Tongva, lived along the river."

A. The trees

B. The river

C. The first people

D. The people who visit a place
4. "... Los Angeles was an agricultural village ... with large areas of cornfields, orange groves, vineyards and cattle* ranches..." (Note: "cattle" means "cows.")

\section{A. Los Angeles had many farms}

B. Los Angeles had a lot of beaches

C. Los Angeles had a lot of buildings

D. People in Los Angeles ate oranges

5. "... the Treaty of Guadalupe Hidalgo made California part of the United States.
A. Treatment
B. War
C. Agreement
D. Government

6. "The Los Angeles Aqueduct brought water from the Owens Valley to Los Angeles."
A. Something that transports water
B. Something that transports people
C. Something that transports valleys
D. Something that transports cars

7. "... some of the most desirable land was along the rivers."
A. Likable
B. Disgusting
C. Decided
D. Worst

8. "In areas with concrete*-lined channels, no water soaks into the ground...." (Note: "concrete" refers to a solid building material.)
A. Comes out
B. Goes in
C. Dries up
D. Stays on top 


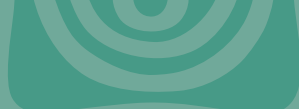 \\ ras \\ (5 minutes) \\ Have students check their answers together, justifying their choices using context clues. Pay particular attention to the vocabulary words "concrete," "soak," "agricultural," "flood," and "flow," since students will encounter these words several times throughout the curriculum.}

\section{Practice 3B: Comprehension Questions}

(40-60 minutes)

1. Introduce Exercise 5 to the students. Tell them that they will read three passages (in Exercise 6) and be asked questions about each passage, and that they will discuss what they read with each other.

2. Have students read the questions in Exercise 5 out loud.

3. Split the class into three groups: I, II, and III. If the groups are too large, break them down into smaller groups-two groups in I, two in II, and so on. Ask members of each group to read their assigned passage in Exercise 6 independently (to themselves). While they read independently, circulate among them and encourage them to use context to guess the meanings of unknown words.

4. Ask students to review what they read, being sure that every student can answer the questions in Exercise 5 and understands all of the vocabulary.

5. Form new groups containing one member from group I, one from group II, and one from group III. Have each person present what they read to their new group, beginning with the student who read Passage I.

\section{Questions for Passage I}

1. Describe the Los Angeles River before Europeans came to Los Angeles. (It flowed across large areas, marshes, and streams.)

2. Who lived here at that time? (The Chumash and Tongva.)

3. When and why did the area change? (Spaniards came and built missions, farms, and so on.)

4. What kind of village was Los Angeles? (An agricultural village with many orange groves, vineyards, cornfields and cattle ranches.)

5. Name four things that happened in the 1820s. (California became part of Mexico; the amount of agriculture increased; French and American people came; Los Angeles became an important area for wine production.)

Questions for Passage II

1. What happened in 1848? (California became part of the United States.)

2. Where did people in Los Angeles get their water from? (The Los Angeles and San Gabriel Rivers.)

3. What important event happened in 1876 ? (The transcontinental railroad was built.) How did this affect the Los Angeles River? (There wasn't enough water for everyone.)

4. Name three changes that happened in the area at that time. (Many people moved to Los Angeles; farmers sold their land; farms moved away from the city center.)

5. How did engineers solve the problem of getting enough water to everybody? (They built aqueducts.)
Lesson 3 " page 22 
6. Complete the following chart about the three aqueducts.

\begin{tabular}{|c|c|c|c|}
\hline YEAR & 1913 & 1941 & 1960's \\
\hline NAME & LA Aqueduct & Colorado River Aqueduct & California Aqueduct \\
\hline BEGINS IN & Owens Valley & Colorado River & Feather River \\
\hline
\end{tabular}

Questions for Passage III

1. What are two things the Los Angeles city government spends a lot of money on? (Getting water in and getting water out.)

2. What is the land like near the river? (Flat.)

3. What happens to floodplains when it rains a lot? (There are floods.)

4. Why did the government build concrete channels in the LA River? (To avoid the danger of the floods.)

5. What are the benefits and drawbacks of channelization? 


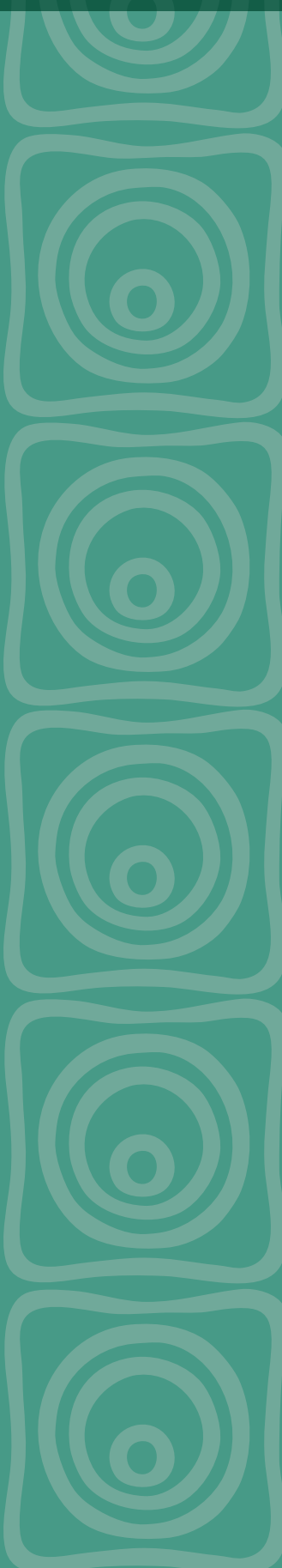

\section{Exercise 6: THE LOS ANGELES RIVER: READING PASSAGES}

\section{Early Days}

Before Europeans came to Los Angeles, the Los Angeles River flowed across large areas of the flat Los Angeles plain. There were large marshes and tree-lined streams.

Father Juan Crespi, one of the first Spaniards to visit Los Angeles in the early 1800s, wrote that the forest along the river was "green and lush." The native Chumash and Tongva lived along the river and used the water for many things. They made paths along the river to move from the mountains to the ocean.

The first Spaniards to build their homes in the area were priests. They built missions along the Los Angeles River in the San Fernando Valley and along the San Gabriel River in San Gabriel. Later, other Spaniards founded El Pueblo de la Reina de Los Angeles, or The City of the Queen of the Angels, along the sides of the river (near what we call "downtown" today).

At that time, Los Angeles was an agricultural village and the rivers provided water for large areas of cornfields, orange groves, vineyards, and many cattle ranches.

In the 1820s, California became part of Mexico, and agriculture in the Los Angeles area continued to expand. People came here from all over Europe. Several American and French settlers came here and began farming. Eventually the area around downtown Los Angeles became one of the most important wine-producing regions in North America.

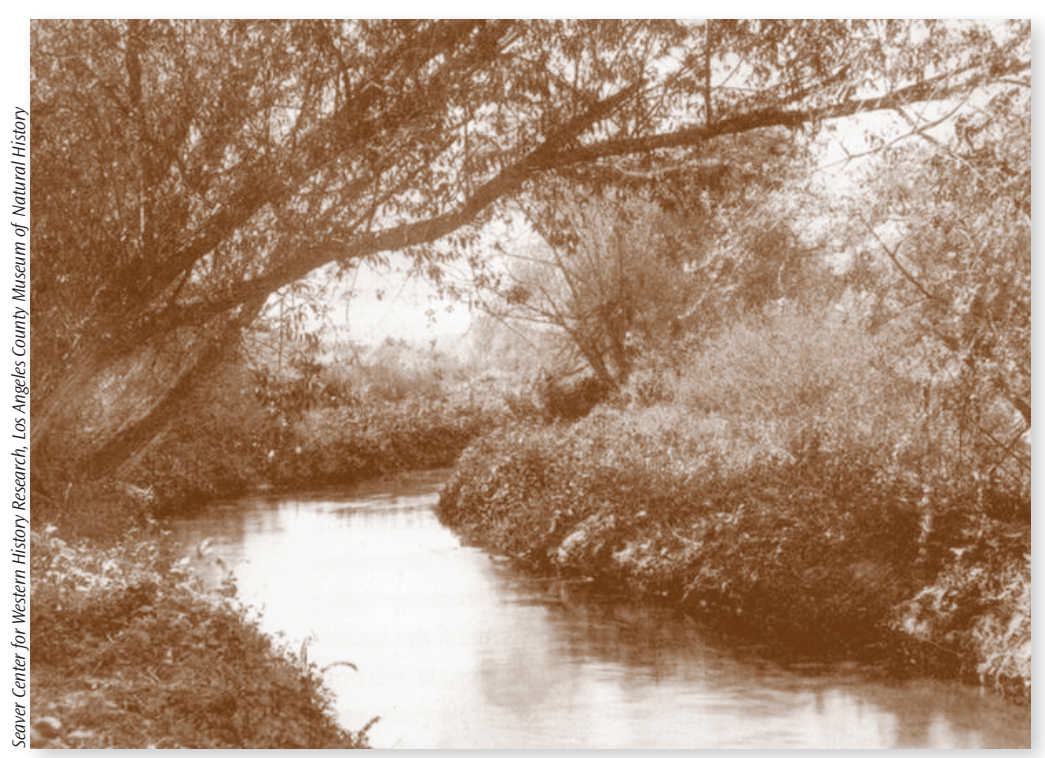

The Los ANgeles River IN THE 1900s. 


\section{Los Angeles Grows}

In 1848, the Treaty of Guadalupe Hidalgo made California part of the United States. At this time, Los Angeles was still an agricultural community that got water from the Los Angeles River. Then the transcontinental railroad was built in 1876 and changed Los Angeles forever.

Because of the railroad, people from other parts of the United States could more easily come to this wonderful, sunny climate. The population of Los Angeles tripled from 33,881 in 1880 to 101,454 in 1890! Many farmers sold their land to home builders. The farms moved away from the city center and went to the north and south along the rivers.

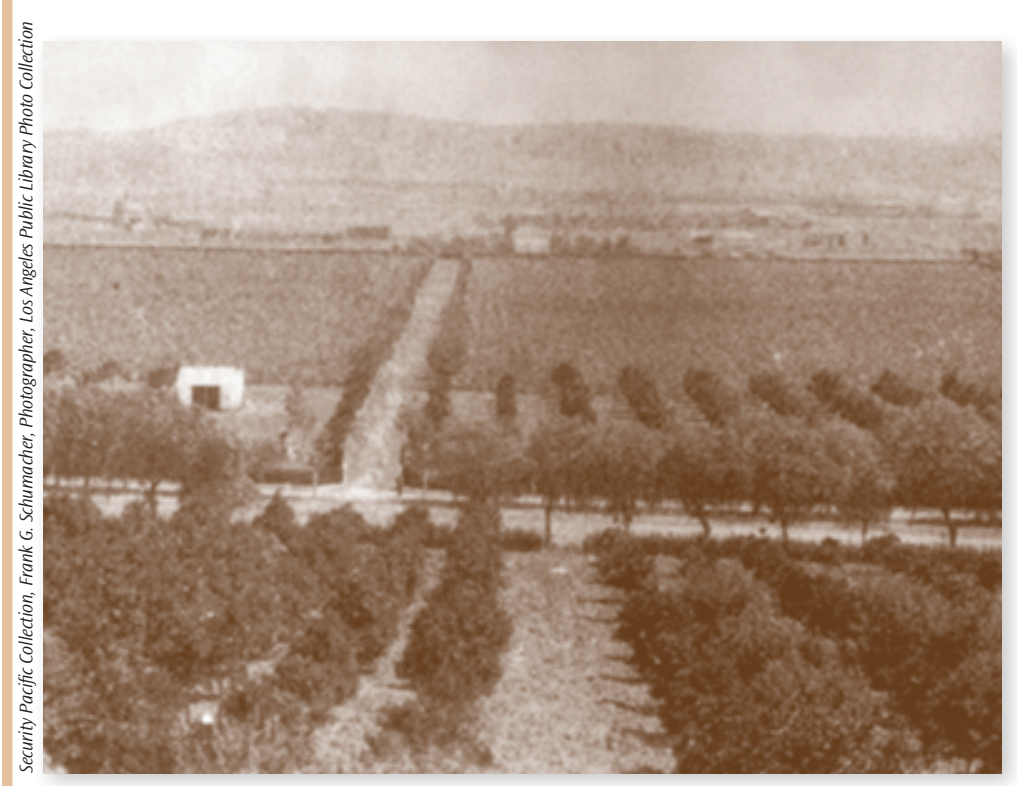

ORCHARDS AND VINEYARDS NEAR LINCOLN HEIGHTS, MID-1900s.
The Los Angeles River could not provide the bigger city and farms with enough water. One of the most difficult engineering projects in the twentieth century began at this time. Three huge canals, or aqueducts, were built to bring water to Southern California from other bodies of water.

The Los Angeles Aqueduct was completed in 1913, bringing water from the Owens Valley to Los Angeles. In 1941 the Colorado River aqueduct was completed, bringing water from the Colorado River to Los Angeles and Southern California. In the 1960s, the California Aqueduct was built, bringing water from the Feather River in Northern California to Los Angeles and the rest of Southern California.

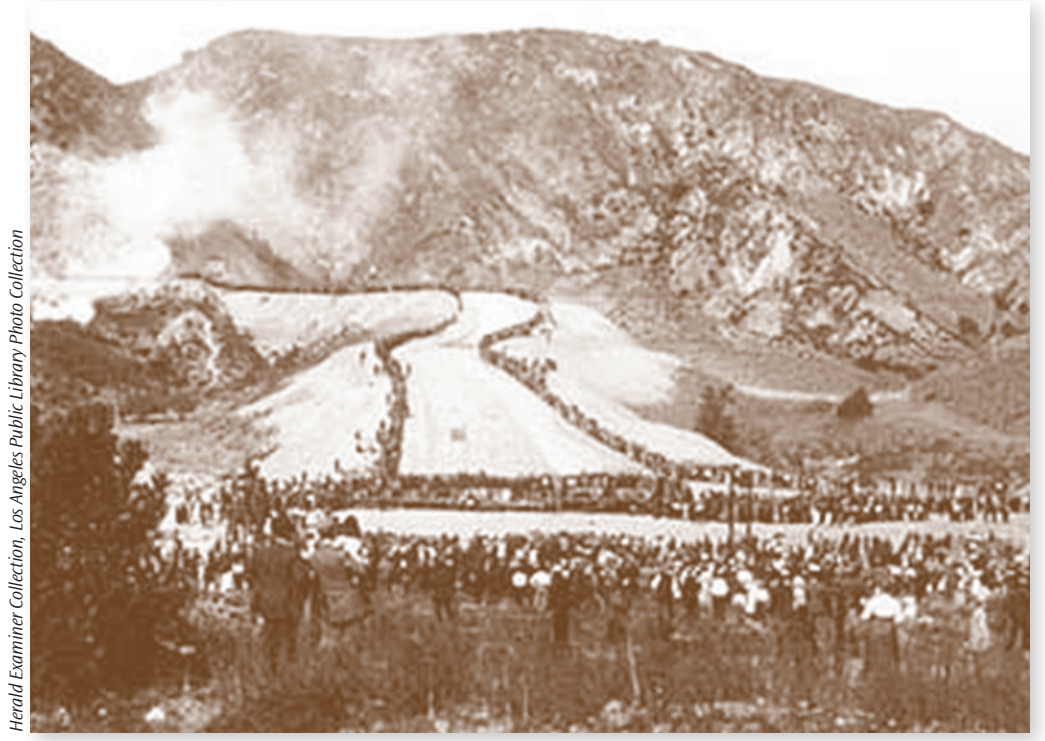

The Los Angeles Aqueduct entering the San Fernando VALLEY, 1913. 


\section{Trying to Control the River}

The City of Los Angeles government spends millions of dollars to get water into Los Angeles. It also spends millions of dollars trying to get water out when it rains. It usually rains only for a short time in Los Angeles, but when it rains, it rains a lot. In fact, the Los Angeles River might be dry in the summer, but it can rise several feet during a storm!

A large part of Los Angeles is very flat. Sometimes when it rained a lot, the river traveled across this flat land and flooded a very large area called the floodplain. Floods were very unpredictable; nobody knew exactly when they would come. On New Year's Day 1934, a very large flood washed away bridges and houses and killed over 80 people.

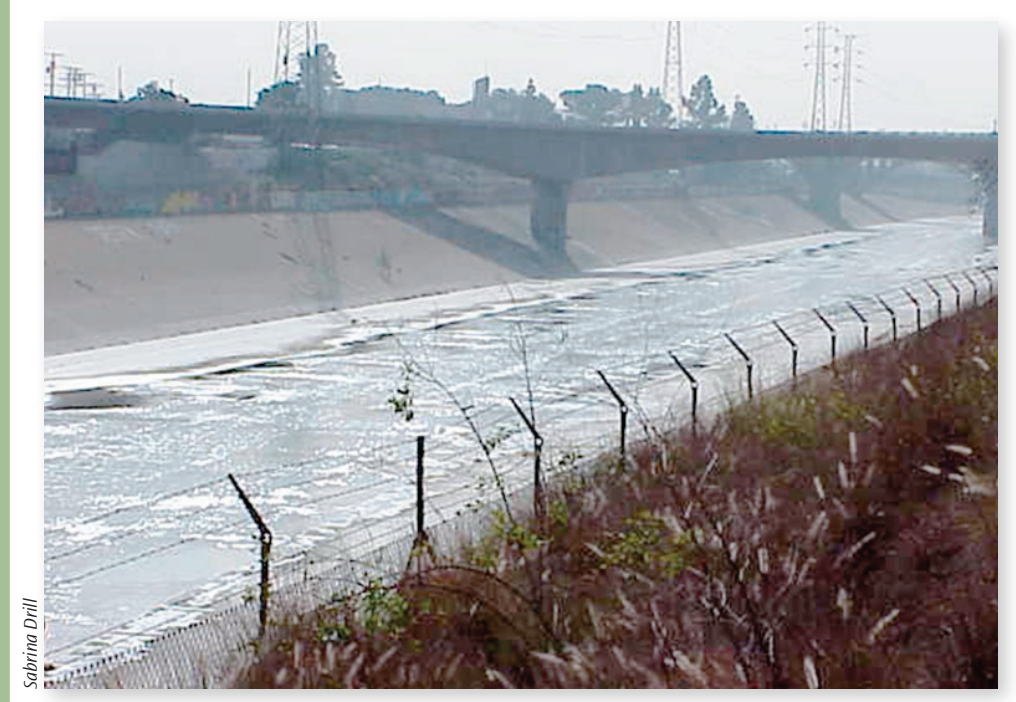

THe Los ANgELES River IN A CONCRETE CHANNEL NEAR DOWNTOWN, $1990 \mathrm{~s}$.
After this, the government of Los Angeles decided to build huge channels made from concrete (see the picture above) to hold the Los Angeles River. This is called channelization. These channels reduced the danger from flooding and kept the residents of Los Angeles safe from floods.

Unfortunately when the Los Angeles River was channelized, we lost many of the good things about the river. For example, plants cannot grow through the concrete. Without plants, the birds, fish, and other animals that used to live in the river cannot survive. Also, plants can help take some of the chemicals and other pollution out of the river. As you can see, there are benefits and drawbacks to channelization. 


\section{Evaluation 3B}

Once all of the groups have presented their passages, discuss them as a class, asking the following questions.

1. In the very early days of Los Angeles, where did people in Los Angeles get their water from? (Los Angeles and San Gabriel Rivers.)

2. What was the land like near the river? (Flat.)

3. Name four things that happened in the 1820s. (California became part of Mexico; the amount of agriculture increased; French and American people came; Los Angeles became an important area for wine production.)

4. What important event happened in the 1876? (The transcontinental railroad was built.) What happened as a result? (More people came, creating the need for more water.)

5. How did engineers solve the problem of getting enough water to everybody? (They built aqueducts). What are the names of the the aqueducts and where do they begin? (Los Angeles from the Owens Valley, Colorado River from the Colorado River, and California from the Feather River in Northern California).

6. What is a "floodplain"? (Flat land around a river.)

7. Why did the government build concrete channels in the Los Angeles River? (To protect people and the city from floods.)

8. What are the benefits and drawbacks to channelization?

\section{ASSESSMENT - (can be done as homework)}

At the end of the lesson, students should be able to answer the following questions in English.

1. Name two or more rivers or streams near your school, neighborhood, or community.

2. Why do many place names in California come from Spanish words?

3. Where do people in Los Angeles get their water?

4. Why does the Los Angeles River have concrete channels?

5. What are the benefits and drawbacks of channelization?

\section{WRAP-UP}

Remind students that they have learned many new words related to water and have shared ways to conserve water. In addition, say that they now know more about the history of the Los Angeles River and water issues in Southern California. Tell them that in the next lesson they will look at how the water in their area is connected to the oceans. 


\section{EXPANSION}

\section{Writing}

Find the river or body of water nearest your home or school. Take your journal there and write about everything you see. Are there concrete channels? If so, what do they look like? Are there birds, animals, or plants there? Do you think in a storm that the river could rise? How much water is there? Did you think there would be more or less?

\section{Family Activity}

1. "Daylighting" is when people remove concrete and asphalt to find streams underneath. People in many cities are daylighting. To find more information, go to www.google.com and search for "stream daylighting" and the name of your city or visit www.urbancreeks. org. You can also find out about urban streams by going to www. northeasttrees.org.

2. FOLAR. In many places, neighbors have decided to form groups to take care of their local river. Often these are called "Friends of" groups. Use the Internet to search for "friends" and the name of your local river. Or, you can learn more about Friends of the LA River (FOLAR) at www.folar.org. This is a group of people who want to help clean up the Los Angeles River so that everyone can enjoy it. Every year they have a River Clean Up Day (in Spanish, La Gran Limpieza), and thousands of people help clean up different parts of the river. If the Los Angeles River is not in your community, see if you can find information about the bodies of water near you.

\section{Guest Speaker}

Ask your children, other family members, or your children's teacher if they know of someone who has more information about the water in your community. Schedule an appointment with your teacher to have him or her come in and talk to your class.

\section{Grammar}

Review "used to" and "didn't use to" to talk about habits in the past. Have the students discuss with a partner what the Los Angeles River used to be like and what it is like now using "used to" and "didn't use to." 


\section{PREPARATION}

As with previous lessons, some exercises are specific to the Los Angeles area. These can be adapted for any bodies of water or watersheds in your community if you prefer to do so.

\section{MATERIALS}

Relief map(s) of the school's community (you can find one at a local map store for under $\$ 30.00$, or check with the geography department at your school); a spray bottle filled with water (colored blue to make it easy to see) (Presentation 1); One road map per 2 or 3 students (you can get these for free at AAA offices) (Presentation 3).

\section{KEY VOCABULARY}

watershed

drain

floodplain

chemicals

pollution

\section{WARM-UP}

(5 minutes)

Ask students what new things they have learned about water (bodies of water, water conservation, rivers in their area, and the history of the Los Angeles River). Ask them to call out some new words for water that they have learned (especially review: body of water, ocean, rain, lake, river, flow, drain, flood, spread, floodplain, concrete, and soak). Ask them to tell you five ways they can conserve water. Ask them which features on a map show how their communities have changed.
Ask them what the Los Angeles River used to look like, what it looks like today, and what the benefits and drawbacks to channelization are. Have students write definitions or synonyms for the words in Exercise 1. Let them know that they will learn more about these words throughout the lesson.

\section{INTRODUCTION}

\section{(5 minutes)}

Tell students that in this lesson they will discuss and learn what watersheds are, how important they are for water quality, and how to keep their watersheds clean.

\section{PRESENTATION 1: WHERE DOES THE WATER FLOW?}

(5-10 minutes)

1. Pass around the relief map (if you have only one). Have students run their fingers over it. Ask them how this map is different from the maps they studied in the previous lesson. Tell them that this is called a relief map (write on board), which is a 3-D plastic model that shows topography (the surface features like mountains, rivers, and valleys). Ask which features are contained on this map and how they can recognize them (e.g., mountains: bumpy; rivers: deep and blue; valley floors: deep, brown, or tan).

2. Ask students to identify their school's location on the map and to discuss what the area feels like. Have students complete Exercise 2, in which they describe what their area looks and feels like on the relief map. 
LESSON

\section{Objectives:}

To name the characteristics of a "watershed" To determine the connection between you, your community, and the bodies of water in your community

\section{To locate your community watershed \\ To list ways \\ of keeping watersheds clean}

3. Tell students to imagine that they live at the top of one of the mountains on the map and that one day it rained a lot. Use the spray bottle to spray water on the map and say that this is what happens when it rains. Have students observe the water running down the map. Ask which parts of the map get wet first. Have them observe where the water goes after it is in the mountains. Ask where it ends up (in the oceans or bodies of water). Say that the water drains, or sheds, from the mountains to the oceans (write "drain" and "shed" and have them repeat). Tell them that everywhere the water traveled, from the top of the mountain to the ocean, is called a watershed (write on the board and have them repeat it). Tell them that watersheds are all the areas that shed water into one place. Write "Watershed = All the land that sheds water into one place."

\section{PRESENTATION 2: WHAT ARE WATERSHEDS?}

(20-30 minutes)

Tell students they are now going to learn more about watersheds. Ask them to listen first with their workbooks closed as you read them the cloze exercise passage below (Exercise 3).

\section{Cloze Exercise Passage (Exercise 3)}

\section{What Are Watersheds and Why Are Watersheds Important?}

What is a watershed? A watershed is the area of land that drains into a specific body of water (such as a lake, river, or ocean).

When it rains, the water flows across the land or soaks into the ground. This rainwater and all of the places the rainwater touches before it arrives at a body of water are part of a watershed. Therefore, if the water touches a mountaintop, building, road, garden, the top of your head, or anything else, those are also parts of the watershed.
A watershed is named for the body of water it flows into. The water that flows from the San Gabriel Mountains across the Los Angeles area drains into the Los Angeles River or the San Gabriel River. If the water drains into the Los Angeles River, the water and the land it flows over is called the Los Angeles River watershed. If it goes into the San Gabriel River, the water and land that it flows over is called the San Gabriel River watershed.

Why are watersheds important? Remember, the water in watersheds flows into a body of water. Bodies of water give us water to drink, wash, and grow food. We also use the water in factories, power plants, and other industries. Bodies of water also provide the water for plants to grow, for fish to live in, and for other animals to drink.

If a watershed is polluted, the body of water it flows into might be polluted too. Your watershed is all around you. What does yours look like?

\section{Practice 2}

\section{(15-20 minutes)}

Now tell students to open their workbooks, and as you (or students) read the passage a second time, they should fill in the blanks with the words they hear.

\section{Evaluation 2}

\section{(10 minutes)}

Have students check the missing words in pairs, then correct as a class. Discuss the proper spelling of the words. Ask, "What is a watershed?" (It is the area of land that drains into a body of water.) Then ask, "What are three reasons to protect our watersheds?" (To avoid flooding, so humans and plants have water, and so the oceans and beaches stay clean.) Tell them (if they're not already familiar) that the exercise they just did is called a "cloze" exercise and that they will find more exercises like it in future lessons. 


\section{PRESENTATION 3: TWO WATERSHEDS}

(30-45 minutes)

1. Tell the students that they will follow the Los Angeles River and San Gabriel River watersheds from their beginnings all the way to the ocean or river they end up in.

2. Split the students into teams of two or three and give each group a AAA map (or other local paper map) to find the communities mentioned in the descriptions of the watersheds in Exercise 4. Tell them to assign one person as the "reader" for the group, and the other person or people will follow with their fingers along the map as the reader tells them where to go. Have them switch readers for the second passage in Exercise 4.

\section{Practice 3}

Have students complete Exercise 4 in pairs or groups.

\section{EXERCISE 4: TWO WATERSHEDS}

The Los Angeles River watershed covers 831 square miles (2,152 square kilometers). The Los Angeles River begins in the Santa Susanna, Santa Monica, and San Gabriel Mountains. From there it flows down through the center of Los Angeles, where it passes Griffith Park, through the Glendale Narrows, and past downtown, Downey, Compton, and Lakewood. It meets the Pacific Ocean at Queensway Bay in Long Beach. The San Gabriel River watershed includes 635 square miles (1,644 square kilometers). The San Gabriel River starts in the San Gabriel Mountains in Angeles National Forest, to the east of the Los Angeles River. From the east, it flows along the eastern side of the Los Angeles plain, past Azusa, Baldwin Park, El Monte, Santa Fe Springs, Norwalk, Cerritos, and Los Alamitos. It meets the Pacific Ocean at Alamitos Bay between Long Beach and Seal Beach.

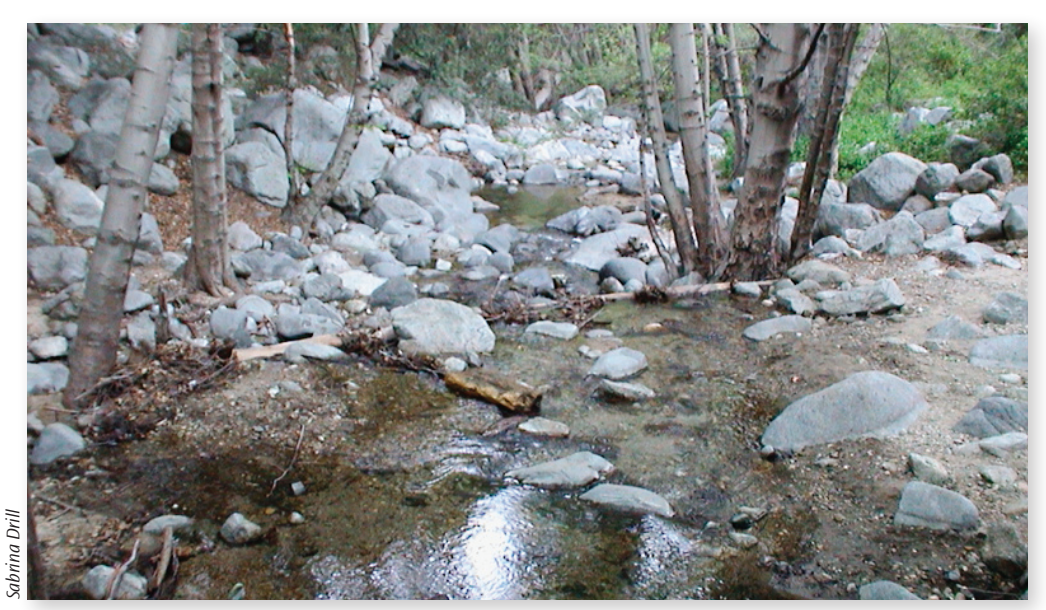

Arroyo Seco, above Pasadena.

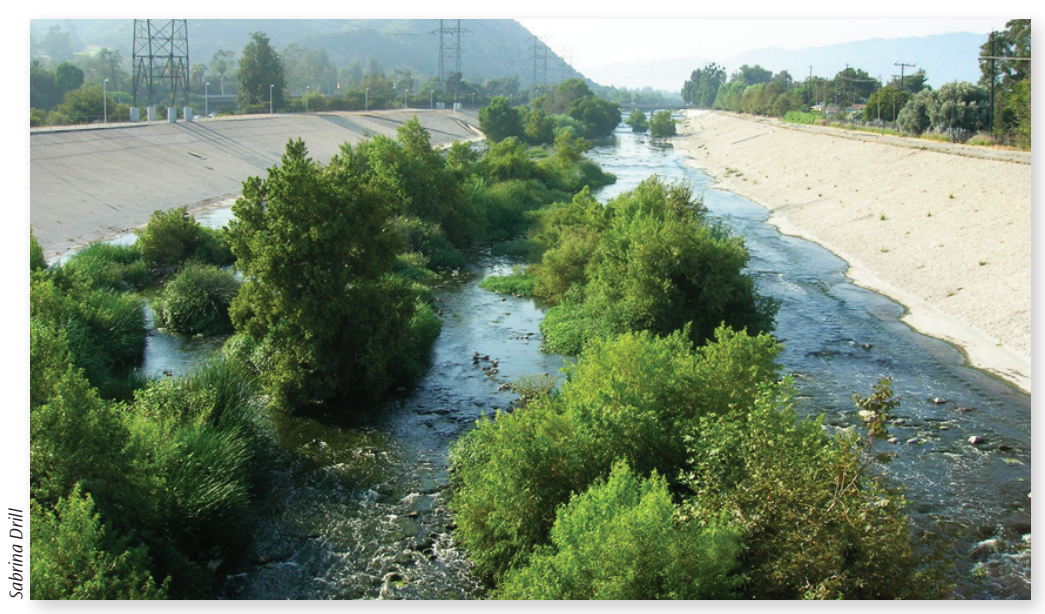

THe Los ANGeles RIVER IN A CONCRETE CHANNEL NEAR Griffith PARK. 


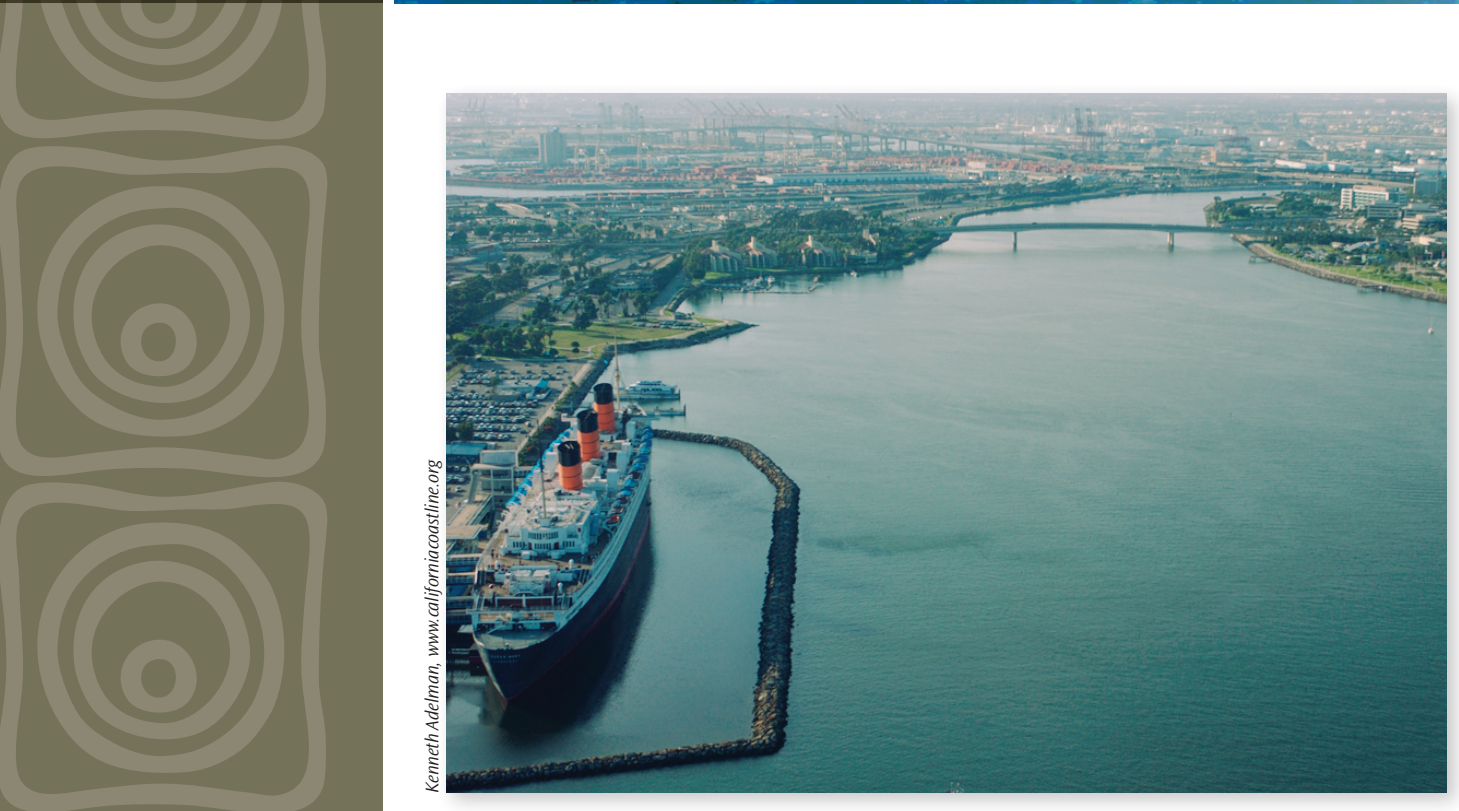

Mouth of the Los Angeles River, Queensway Bay, Long Beach

\section{Evaluation $3 \mathrm{~A}$}

(5 minutes)

Discuss with students the similarities and differences between the two watersheds. Ask what their neighborhood watersheds are like: Are they bigger or smaller than those above? Where do they flow to?

\section{Practice 3B: Protecting Our Watersheds}

(10 minutes)

Ask students in pairs or groups to brainstorm different ways to protect watersheds (Exercise 5).

\section{Evaluation 3B}

(5 minutes)

Have students share their ideas with the class.

\section{Practice 3C}

(45-60 minutes)

Group students and have them create a poster using the ideas generated in Exercise 5 to help educate people in their community about keeping the watersheds clean.

\section{ASSESSMENT}

At the end of the lesson, students should be able to answer the following questions in English:

1. What is a watershed and why is it important?

2. What is the watershed in your community called?

3. What are some solutions for keeping watersheds clean?

\section{WRAP-UP}

Tell students that now they have learned words for water, that water is vital, how to conserve it, all about the water in their areas, and the connection between their communities and the rivers and oceans. Say that in the next lesson they will learn more about keeping watersheds and bodies of water clean. 


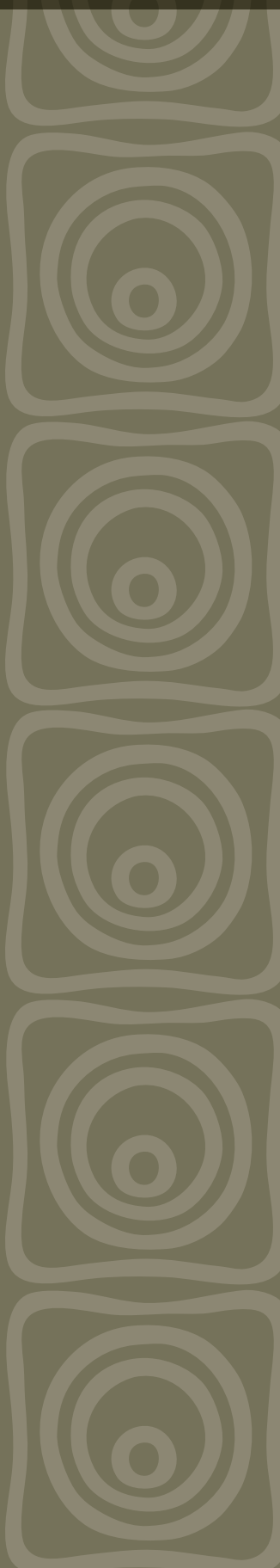

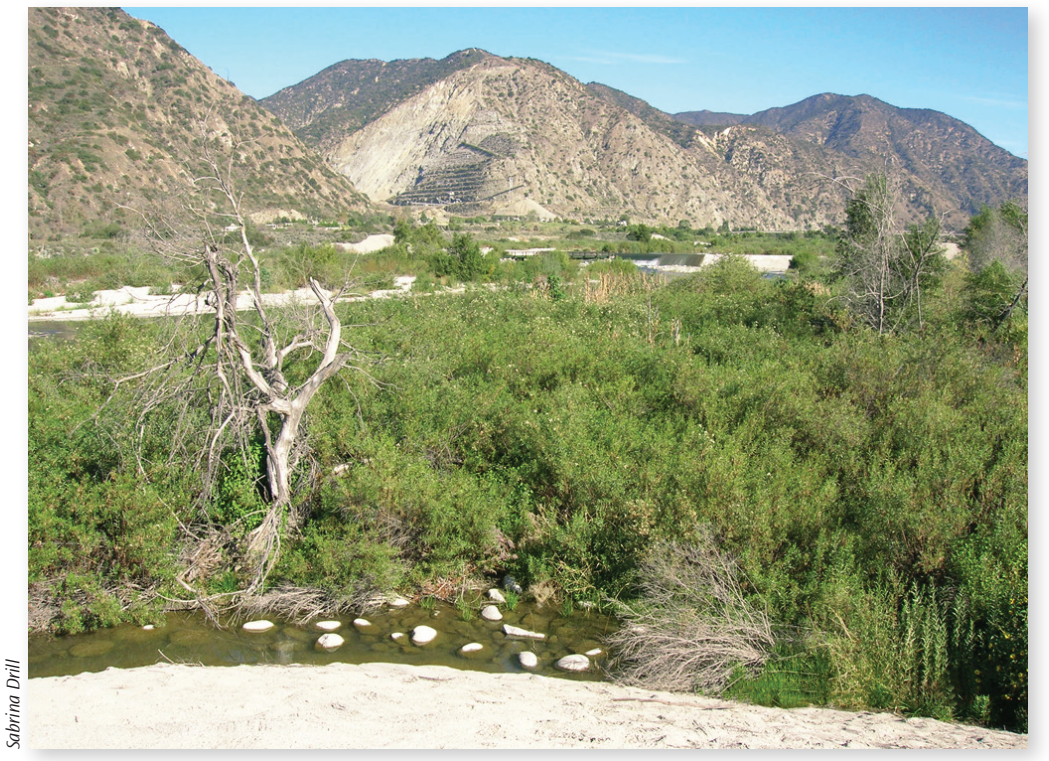

The San Gabriel River leaving the San Gabriel Mountains, NEAR DUARTE.

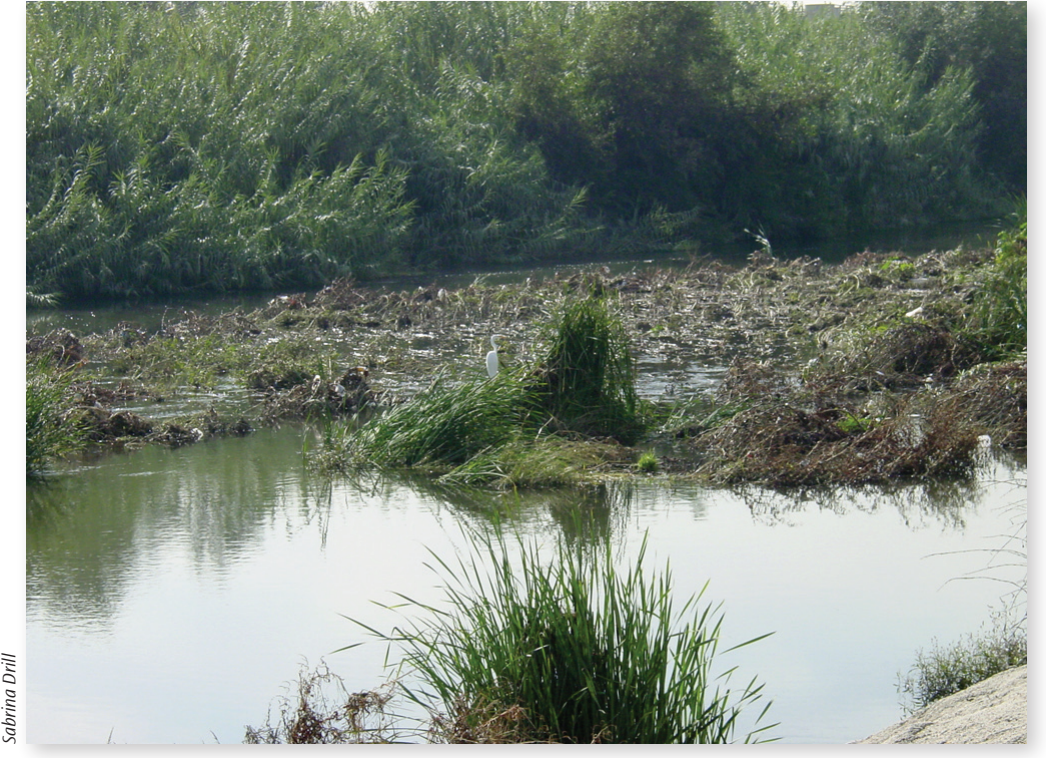

The San Gabriel River near Whittier Narrows.

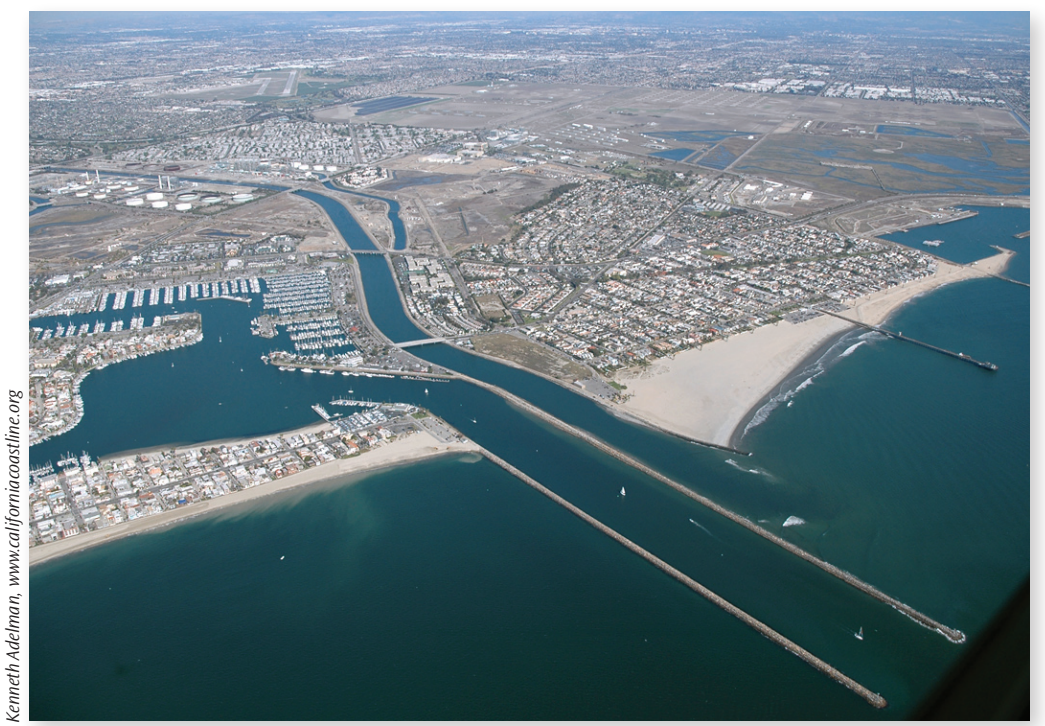

Mouth of the San Gabriel River, Alamitos Bay. 


\section{EXPANSION}

\section{Writing}

Look up the word "watershed" in an English dictionary. You will find that there is more than one definition of a watershed. Which definition fits with what you learned in this lesson? Once you've learned the different definitions, write, draw, or paint examples of each.

\section{Family Activity}

1. With your family, visit these Web sites that have important information about watersheds:

- Center for Watershed Protection: www.cwp.org

- Heal the Bay: www.healthebay.org

- LA and San Gabriel Rivers Watershed Council: www.lasgrwc.org

- Watershed Management Council: www.watershed.org

Find out whether they have any upcoming events or meetings that you and your family can attend.
2. Name your watershed. To find out what watershed you live in, go to the "Surf your Watershed" page of the Web site for the U.S. Environmental Protection Agency, http://cfpub.epa.gov/surf/locate/, and type in your zip code. What does it say? Do you have friends or relatives who live in other parts of Los Angeles, California, or other states in the United States? Type in their zip codes, and see which watershed they live in.

\section{Grammar}

Review the modal verbs "should," "must," and "have to" in statements and questions. Then give your classmates or family members advice for taking care of the watersheds in their communities. 


\section{Reducing Water Pollution}

\section{Objectives}

\section{To define}

"pollution"

To compare

point source

and nonpoint

source pollution

\section{To compare}

storm drains

and sewers

\section{To share and \\ learn ways to \\ reduce water \\ pollution}

\section{PREPARATION}

Request a copy of the video for Presentation 3: Make the Connection: A Video Tour of Los Angeles's Storm Drain System by calling 1-800974-9794 ext. 3 (also available in Spanish). The City of Los Angeles also plans to post the video on the Web at www. lastormwater.org. Familiarize yourself with the video before showing it to students and arrange to have a television and VCR or DVD player in your room. Cut the statements in the box in Presentation 2 (page 38) into strips.

\section{MATERIALS}

Tape to adhere strips to a blackboard (for Presentation 2); television and VCR; the video Make the Connection: A Video Tour of Los Angeles's Storm Drain System; a thesaurus and dictionary.

\section{KEY VOCABULARY}

pollution

Styrofoam

pet waste

fertilizers

pesticides

gutter

point source pollution

nonpoint source pollution

scanning

storm drain

sewer

\section{WARM-UP}

(5-10 minutes)

In pairs have students discuss the following:

- name all of the water words they have learned so far

- name three things that are vital to human life

- name a body of water near their home or school

- define "watershed" and talk about what watershed they live in

- explain why watersheds are important and how to keep them clean

\section{INTRODUCTION}

(10-15 minutes)

1. Have students look at Exercise 1 in their workbooks. This list appears:

- a Styrofoam cup floating in the Los Angeles River

- oil on the road

- a cigarette tossed into the Ventura River

- pet waste in the street

- fertilizers and pesticides flowing down a watershed

- grass clippings and other trash from yardwork

2. Ask students to use a thesaurus or dictionary to define any unknown words. Next, discuss what all of the above situations have in common. Elicit that they are all bad for water, land, and air. Ask if they know a word used to describe things that are bad for water, land and air. Elicit and write on the board "pollution."

3. Ask students to discuss (in pairs, groups, or as a class) the causes of pollution. Make a list on the board.

4. Tell students that in this lesson they will learn more about the causes of water pollution and share solutions for it. 


\section{PRESENTATION 1: TWO CAUSES OF WATER}

\section{POLLUTION}

(5 minutes)

Tell students they will be listening to a passage about two causes of water pollution: nonpoint source and point source (write these on the board). Review instructions for the cloze exercise (listen with workbooks closed the first time, then fill in the blanks the second time). If you prefer, a student can read the passage from your teacher lesson book.

\section{Practice 1A}

(20-30 minutes)

Read the passage below twice with student workbooks closed the first time and students filling in the blanks of Exercise 2 the second time.

\section{CLOZE READING (Student workbook Exercise 2)}

\section{Paragraph 1}

"Source" means where something begins. "Point" is an exact location. We use these two words to describe different types of water pollution. There are two names for the causes of pollution: nonpoint source pollution and point source pollution.

\section{Paragraph 2}

Point source pollution is pollution that enters a body of water at a specific, identifiable location. An example of point source pollution is when chemicals from a factory flow into a river through a pipe, ditch, or tunnel.

\section{Paragraph 3}

Nonpoint source pollution is not as easy to identify, but it is the biggest source of pollution in the United States. Nonpoint source pollution is pollution that comes from many places. When rain falls and flows on the ground, it picks up pollutants from different places. These pollutants include:

\section{Paragraph 4}

- Lawn chemicals like fertilizers and pesticides.

- $\underline{\text { Oil }}$ and grease from cars and roads.

- Soap from washing your car.

- Sand and concrete from construction sites.

- Soil from crop and forest lands.

- Bacteria from pet waste.

- Bacteria from faulty sewer systems.

\section{Paragraph 5}

As the water flows in our watersheds, the pollutants enter our lakes, rivers, oceans, and eventually, our drinking water. It is difficult to reduce nonpoint source pollution because it begins in so many different places.

\section{Evaluation $1 \mathrm{~A}$}

\section{(5-10 minutes)}

Check the answers as a class. 


\section{PRESENTATION 1B: SCANNING}

(5 minutes)

Tell students that scanning is a good skill to use before they read a passage. Explain that scanning means looking for the main idea or ideas of a passage to become familiar with the topic, but not reading every word.

\section{Practice 1B}

Have students scan reading in Exercise 2, then complete Exercise 3 by filling in the number of the paragraph that describes this main idea.

3 __ Describes nonpoint pollution

4 _ Gives different types of pollutants

1 Defines "source" and "point"

2 _ Describes point source pollution

5 Explains why it is hard to resolve the problem of nonpoint source pollution

\section{Evaluation 1B}

(5 minutes)

Have students take turns reading one or a few sentences each, checking their answers as they read.

\section{Practice 1C}

(10 minutes)

Have students independently read the entire exercise, paying attention to the main ideas of each paragraph.

\section{Evaluation 1C}

(5-10 minutes)

Have students close their books and discuss with a partner the main topics covered in the exercise.

\section{PRESENTATION 2: SEWERS AND STORM DRAINS}

(20-30 minutes)

Tell students that they are now going to study a location where a lot of nonpoint source pollution is found: storm drains. Say that first it is important to understand the difference between storm drains and sewers.

\section{Practice 2}

(30-40 minutes)

Have students work with a partner completing Exercise 4 in their workbooks, guessing whether the sentence describes a sewer or a storm drain. 


\section{Reducing Water Pollution}

As they work, hand each pair one of the statements on a strip of paper with tape attached to the back. Ask them to discuss together which category their strip falls under. Copy the following chart on the board (only the empty boxes and the words "Storm Drains" and
"Sewers" at the top, without the answers). When the students agree on a category, have one go to the board and place his or her strip under the appropriate category.

\section{STORM DRAINS}

Do not clean the water before taking the water into the ocean.

Help to prevent (avoid) flooding.

Usually begin outside on the street.

If food enters, they will attract cockroaches, rats, and flies.

If too much trash fills them, there will be flooding.

\section{SEWERS}

Take water from bathrooms, sinks, washing machines, and toilets.

Clean the water many times before taking the water into the ocean.

Usually begin inside and take water from inside.

If too much trash fills them, there will be flooding. 


\section{Reducing Water Pollution}

\section{Evaluation 2}

(15-20 minutes)

After the students have placed their strips, check their lists. Tell them how many are correct and how many are incorrect in each category. Allow them to come up and switch the descriptions around for as long as you like, or until they have gotten them all into the right place. Once they are all in the correct category, have a student read from each one. Have them look at the picture in their workbook (also shown below) and ask: Is this a storm drain or a sewer? (Exercise 5).

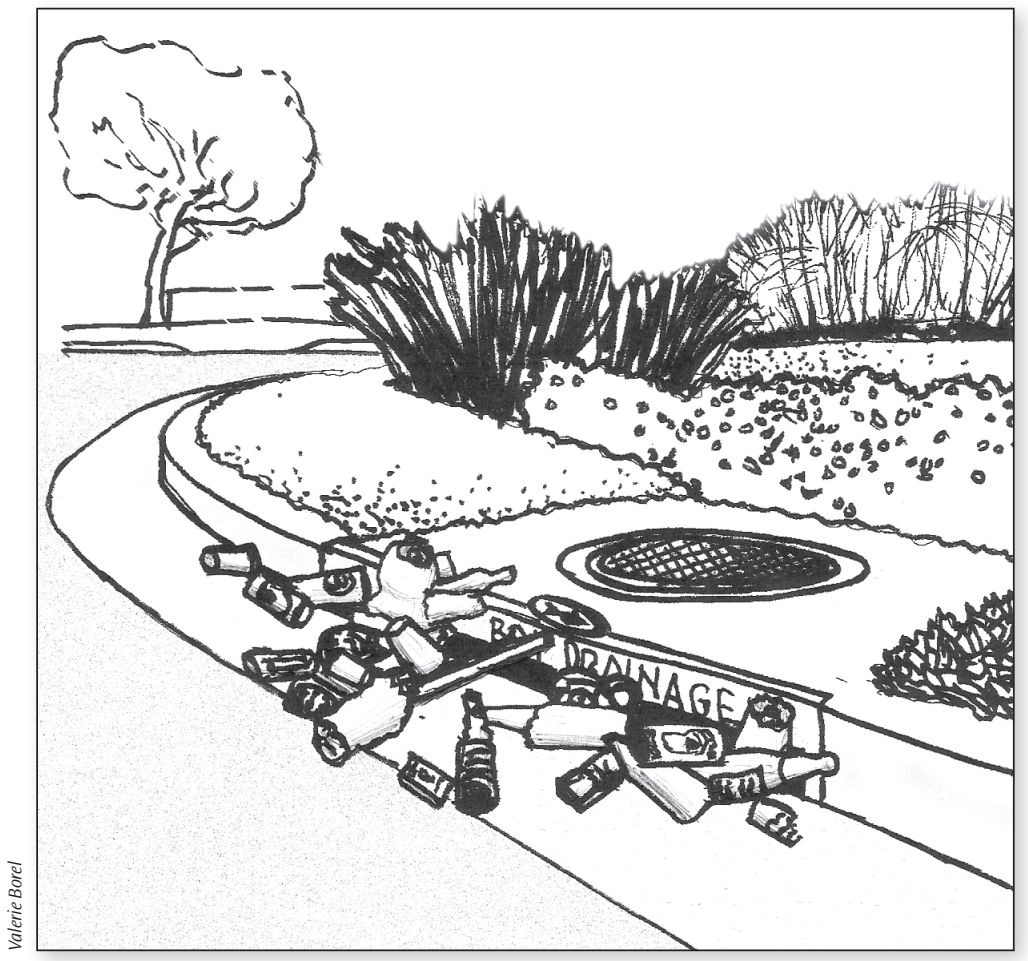

STORM DRAIN.

\section{PRESENTATION 3: LOS ANGELES STORM DRAINS}

(45-60 minutes)

Ask students what the differences are between storm drains and sewers. Tell them that today they will watch a video about the storm drains in Los Angeles. Have students look at the chart in Exercise 6 (see below) in preparation for watching the video.

\section{QUESTION \& ANSWER}

1. According to Chris, Los Angeles has been fighting ocean pollution for a long time. What is the cause of ocean pollution?

A. Sewage

B. Natural disasters

C. Pollution entering storm drains

2. True or False: Sewers and storm drains are the same. False

3. Which system (storm drains or sewers) does not treat waste? Storm drains

4. According to Chris, why is it important to stop trash from entering the storm drain?

We need to stop the trash from entering the storm drain or the trash will flow into the ocean.

5. Where do storm drains start? They start in every neighborhood.

6. What does Chris say that we can do to stop pollution from entering the storm drains?

I clean around my house and my neighbors clean around theirs. 


\section{Practice 3}

(10 minutes)

Show the video Make the Connection: A Video Tour of Los Angeles's Storm Drain System. While watching, students should take notes and write their answers in the boxes provided in Exercise 6.

\section{Evaluation 3}

(5-10 minutes)

Have students check their answers to Exercise 6 in pairs, then check them together as a class. Facilitate further discussion by asking students if they were surprised by the information in the video, what they found most interesting, what the storm drains in their neighborhoods look like, and what they could do in their communities to help keep the storm drains clean. Tell students that if they would like a copy of the video or would like to report pollution in their area, they can call (800) 974-9794.

\section{PRESENTATION 4: REDUCING POLLUTION}

(4-5 minutes)

Review nonpoint source pollution, emphasizing that it is difficult to reduce because it comes from many places. Facilitate discussion on one nonpoint source-storm drains-and why it is important to keep them clean. Tell students that in this part of the lesson they will think of solutions for keeping the water in their areas clean.

\section{Practice 4A}

(45 minutes)

Have students read through the first problem in Exercise 7 (see below) independently and then brainstorm solutions. Have them share their solutions and discuss them as a class. Then have them complete the rest of the exercise in pairs.

1. Mr. Tran has two large trees outside his apartment building. The trees attract wasps, mosquitoes, and caterpillars. He hates the insects, so he sprays the trees with a lot of pesticide to kill them. After he sprays the pesticide, there's a big storm. Where will the rain take the pesticides? What can Mr. Tran do instead?

Answer: Mr. Tran can wait until the storm passes, and then spray his pesticide at the rate recommended on the pesticide label.

2. Natara helps her dad change the oil in his car. After they take the oil out of the car, she carries the huge pan of black, thick oil to the storm drain, where she dumps it. "It's gone!" she says. Where does the oil go next? What can Natara do instead of putting the oil into the storm drain?

Answer: Natara and her father can keep the oil in a safe container that won't leak. Then, they can contact their city's public works department or call their local auto parts store to find out where they can take the oil for proper disposal. They can also take it to a used oil collection event, or to one of the many used oil collection sites around their city.

3. One winter night the Horton family heard raccoons in their garbage cans outside, but it was too cold to go outside and chase them. The next morning, no one had time to clean up the garbage all over the street. Later that day it rained. What happened to the garbage on the street? What can the Horton family do instead?

Answer: The Hortons can make sure that the lids on the garbage cans are secured tightly each night. 
4. Veronica helps her grandparents by cutting the grass in front of her house. When her grass catcher is full, she dumps her grass clippings into a nearby storm drain. There, the clippings turn yellow and begin to smell. What will probably happen next? What can Veronica do instead?

Answer: Veronica should throw the cut grass in the trash, or, if her city recycles green waste, in the green recycling bin. She also can learn to compost these grass clippings by going to a smart gardening workshop. These workshops are offered by the city's public works department.

5. Isabel enjoys walking the family dog, Jack. When Jack needs to go to the bathroom, Isabel is careful to make Jack go along the curb so that Jack is not messing the neighbors' grass. She thinks she is helping to keep her neighborhood clean. What will happen to the dog waste next? What can Isabel do when she walks Jack?

Answer: Isabel can pick up after Jack.

6. The Martin family likes to stop at fast-food restaurants on the way to the beach. They throw their bags of trash out the window so they can keep the car clean. What can the Martin family do instead?

Answer: The Martins can place their trash in a bag and wait to throw it out. They also can receive a traffic ticket (a $\$ 500$ fine plus a court appearance) that may remind them to do so.

7. John is moving into an apartment. He wants new furniture and a new television set, and goes to a store to buy them. When he brings his new furniture and TV to his house, he puts his old sofa and television set out on the curbside. He thinks that whoever wants them can come pick them up. "Everybody does it," he says. What will happen to the furniture and TV? What can John do instead?
Answer: John can call his city's sanitation department and find out that there is no charge for "bulky item pick-up." He can make an appointment with the department at no charge, and the trash truck will pick it up at no charge. John also can donate these furniture items if they are in good condition. He also can call an electronic recycling company to have the television sold for parts at no cost to him.

\section{Practice 4B}

(30-40 minutes at home)

Have students complete Exercise 8 (see below). Tell them that they should report on these in the next class and be able to say which of the scenarios they discussed today can be resolved by contacting the organizations or departments they researched.

\section{Exercise 8: Who Can You Call for Help?}

Research the following groups on the internet to see who can help with the problems listed in Exercise 7.

The public works department can help with \# 2 A smart gardening workshop can help with \# 3

The sanitation department can help with \# 


\section{ASSESSMENT}

At the conclusion of the lesson, students should be able to answer and discuss these questions in English:

1. What is pollution? What is the difference between "pollution," "pollutant," and "polluter"? Are you any of these? Give an example of each.

2. What is the difference between point source pollution and nonpoint source pollution? Give an example of each. Which is the biggest cause of pollution in the United States?

3. What are the similarities and differences between sewers and storm drains? Describe Los Angeles's storm drains.

4. Name five ways to reduce water pollution. Name three resources to search more information about reducing water pollution.

\section{WRAP-UP}

Remind students that now they have learned and shared about the storm drains in their areas. Explain that they have also identified local departments or agencies that can help them keep the water in their communities clean. Ask them whether now when they hear people in their families, communities, or local governments talking about water, they feel that they can share their ideas about how to keep water clean and safe for everyone now and in the future (discuss).

\section{EXPANSION}

\section{Writing}

Reread your first writing called "My Favorite Body of Water." Are there any changes you would make to it? If so, write a new one with those changes. If not, think about water pollution in the country where you were born and write about that. Is the water cleaner in the country where you were born than in your community here? Do you feel that the people in the country where you were born know more or less about keeping water clean than most Americans? Do you think that it is possible for you to help keep water clean in your current community? In the state you live in now? In the world?

\section{Family Activity}

1. Coastal Cleanup Day: What can you do to help clean up rivers and beaches? You can participate in Coastal Cleanup Day in midSeptember, when Californians gather on the beaches and rivers to clean them. Events for Coastal Cleanup Day can be found on the California's Coastal Commission Web site, http://www.coastal.ca.gov/ publiced/ccd/ccd.html.

2. Earth Day: Earth Day is celebrated every year in the third week of April. Look for events all over California in the newspapers during that time.

\section{Grammar}

Review the conditional for hypothetical situations. Discuss what would happen if people continue to pollute water. 


\section{Student Workbook}
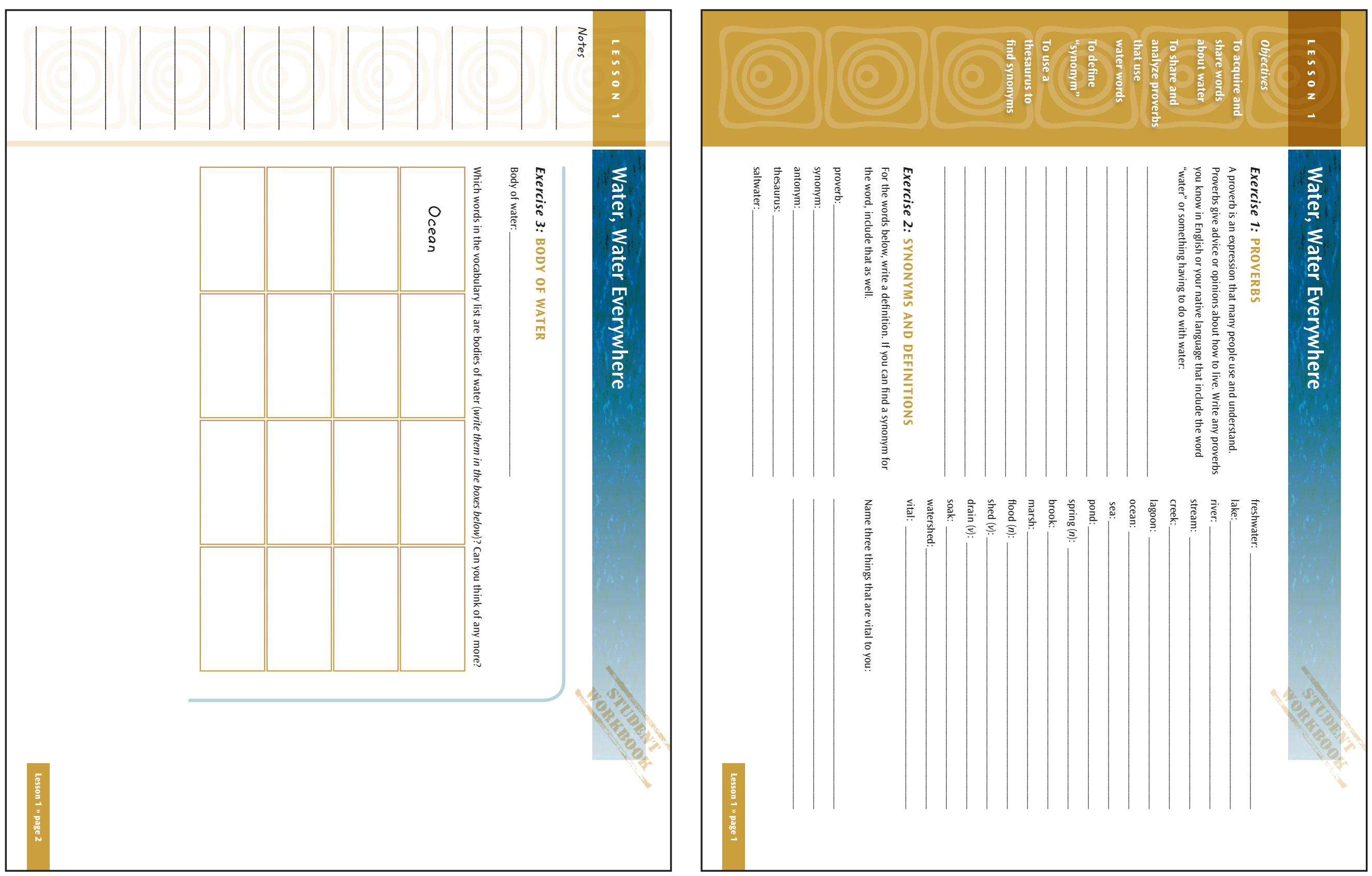


\section{Student Workbook}
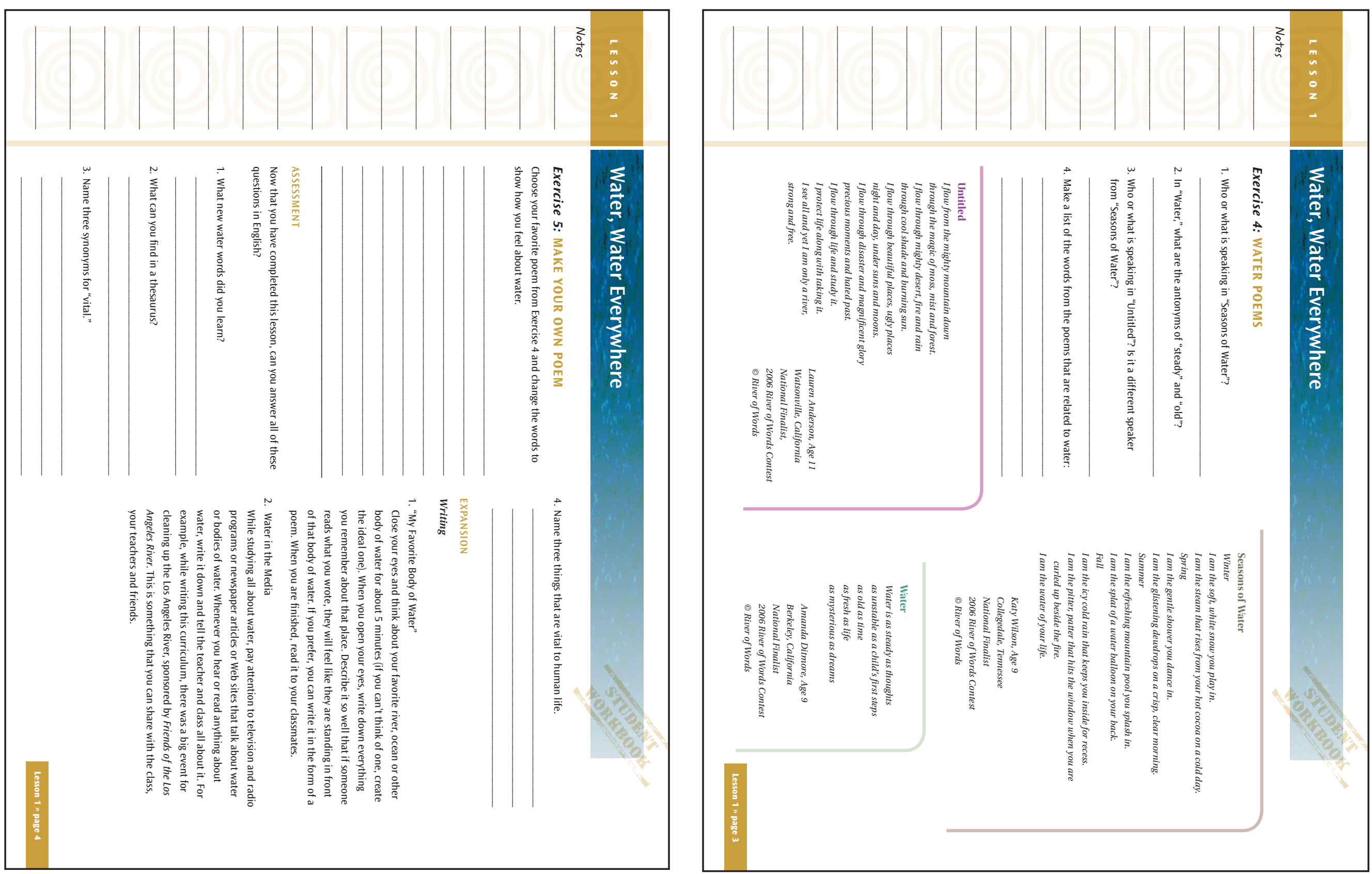


\section{Student Workbook}
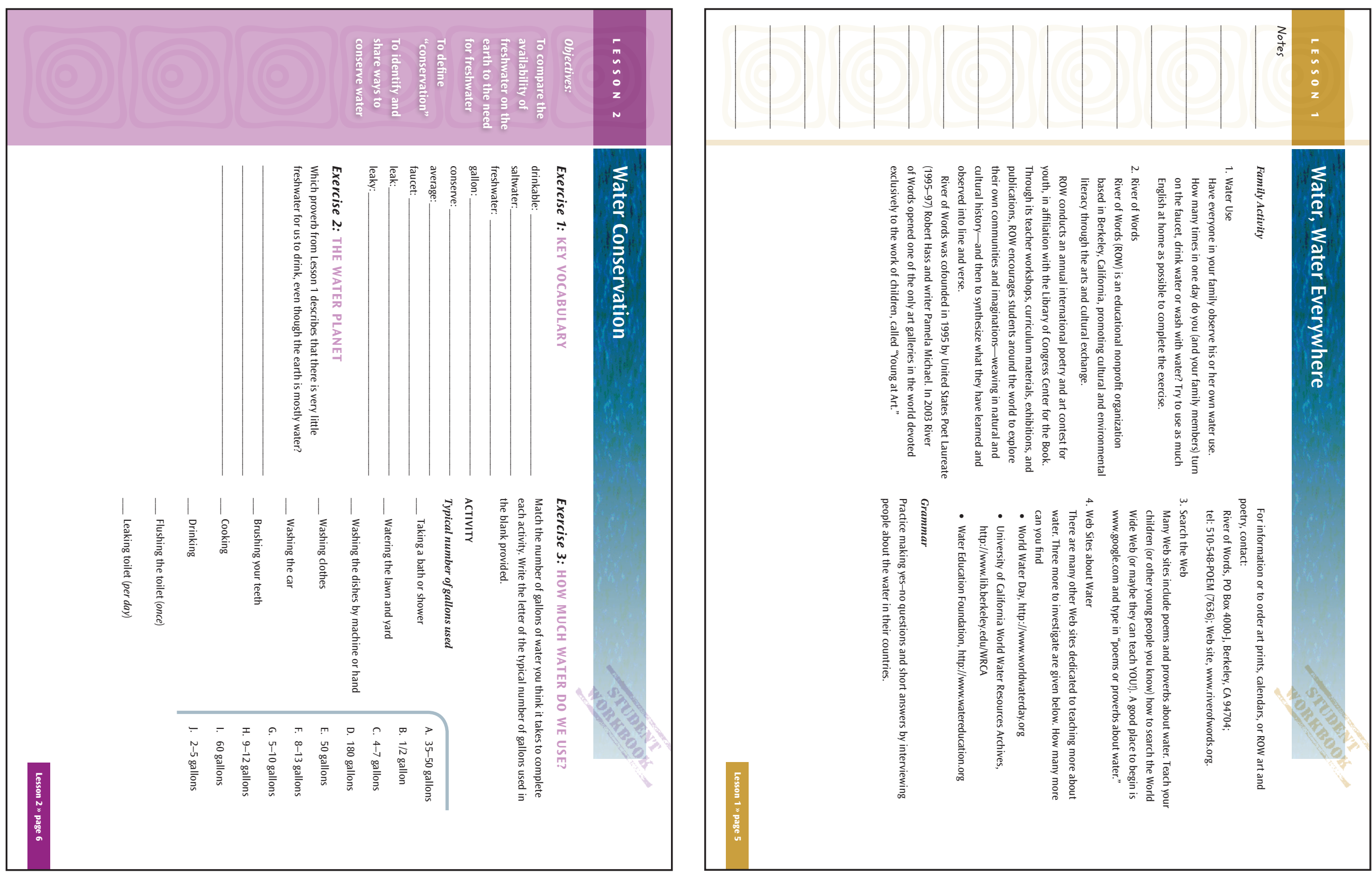


\section{Student Workbook}
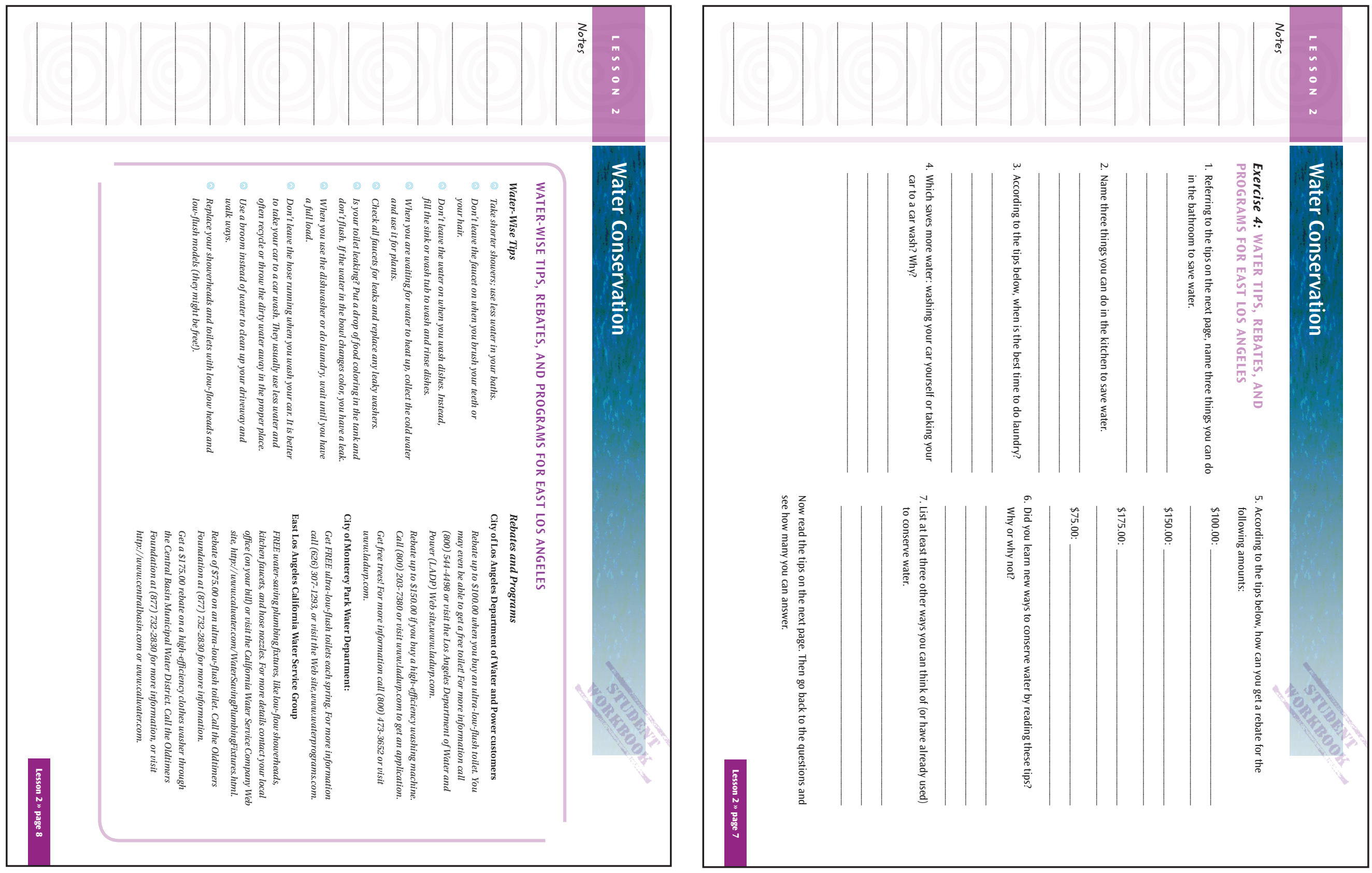

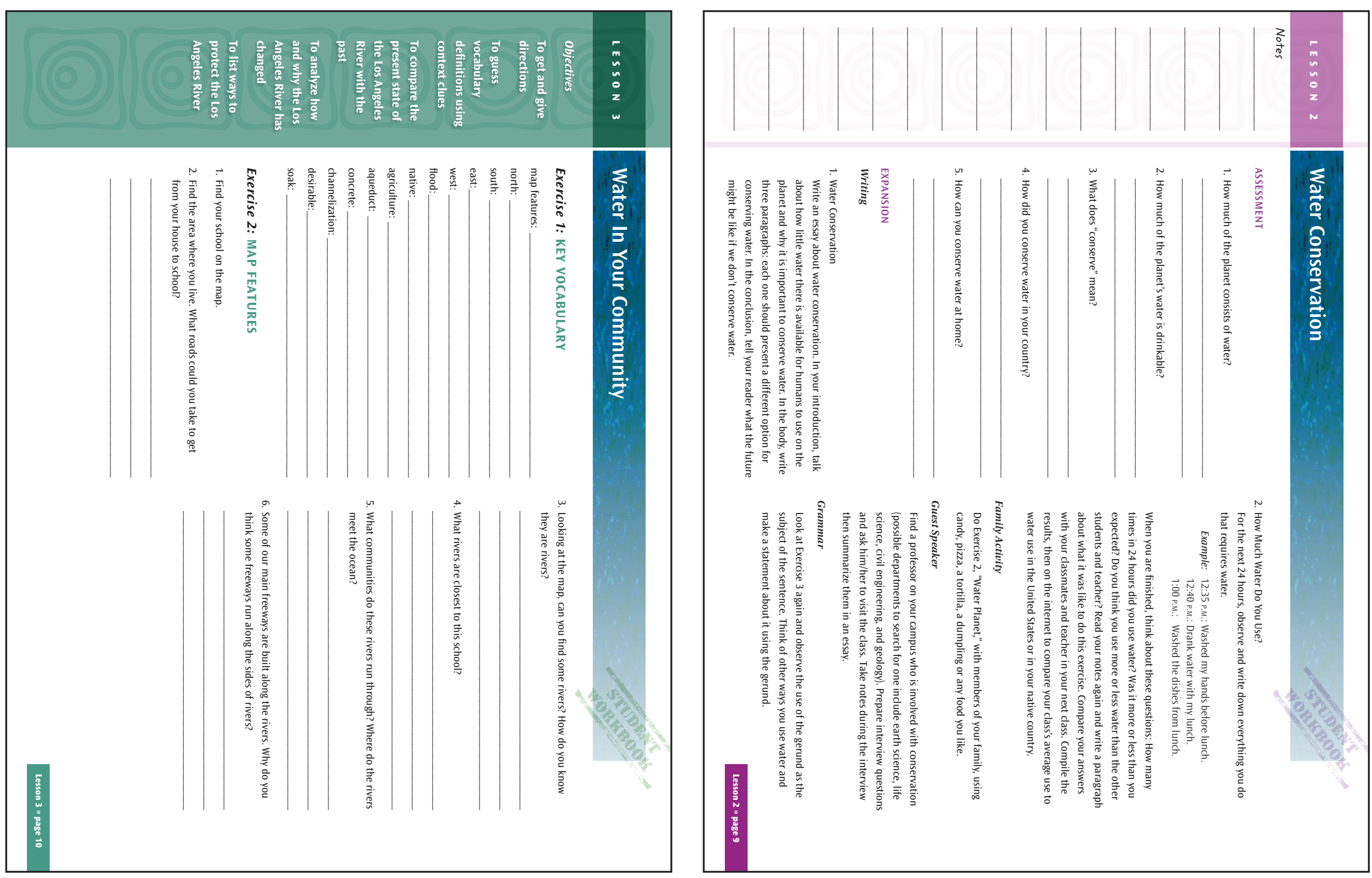


\section{Student Workbook}
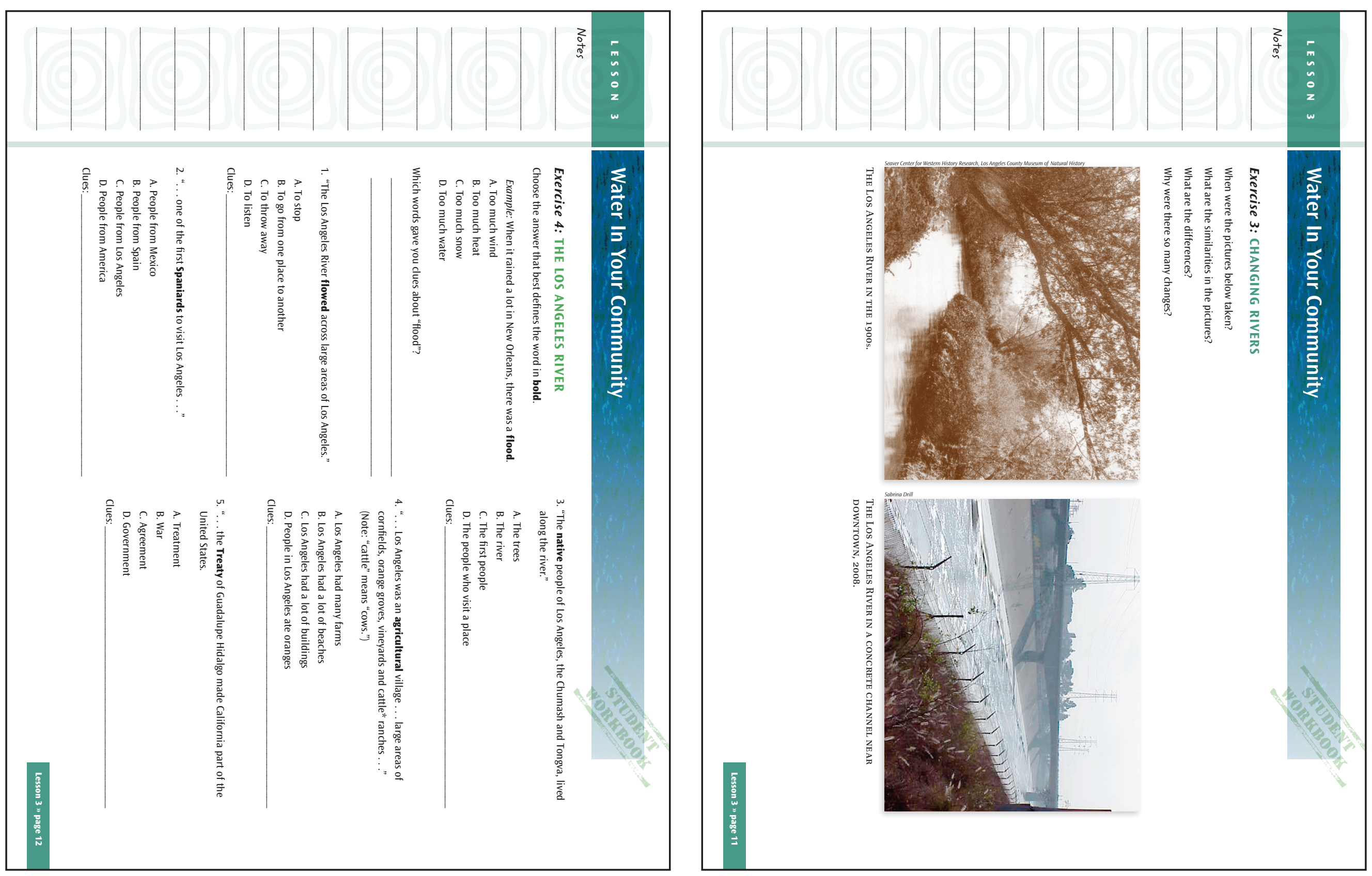


\section{Student Workbook}
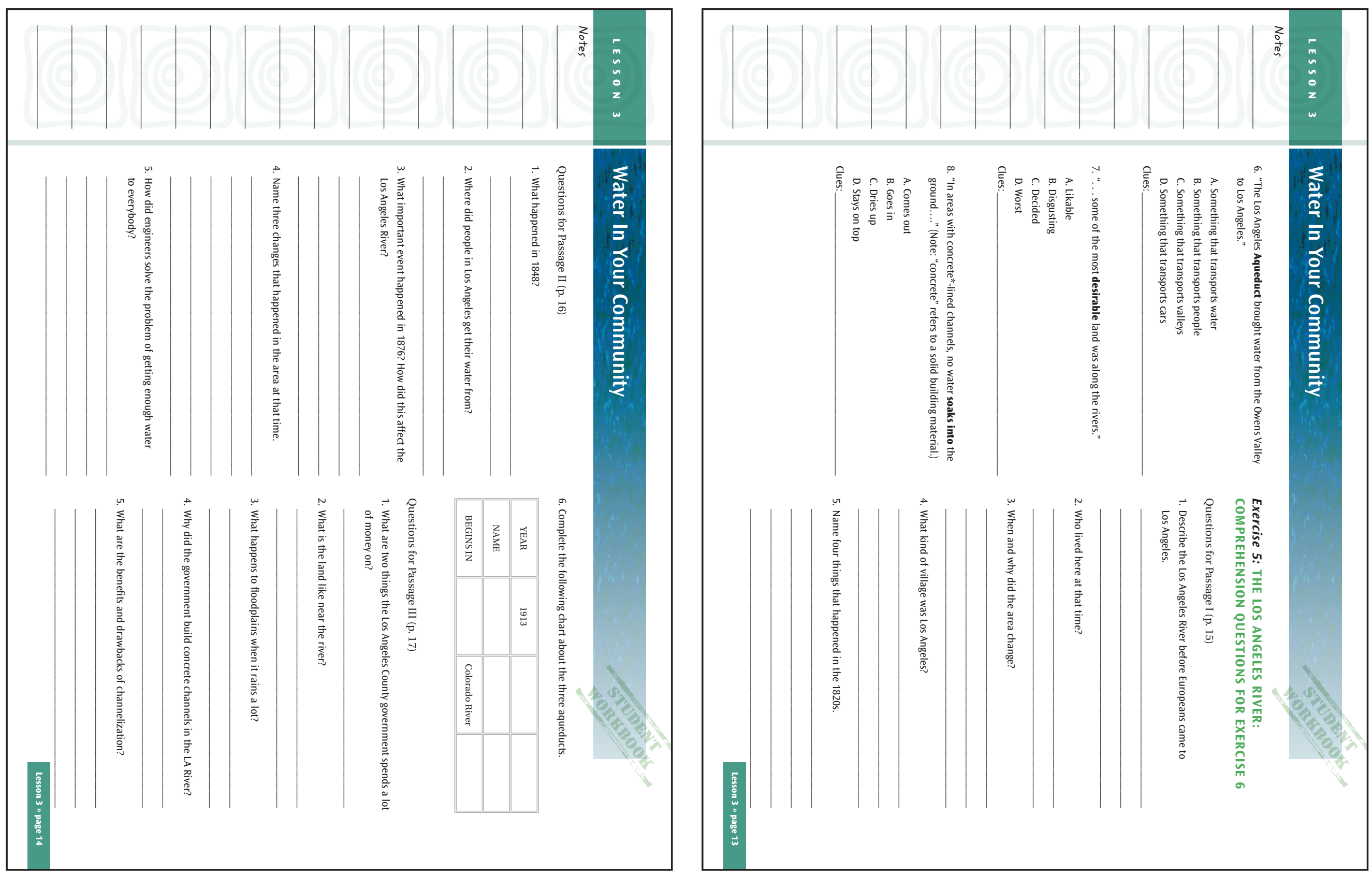


\section{Student Workbook}
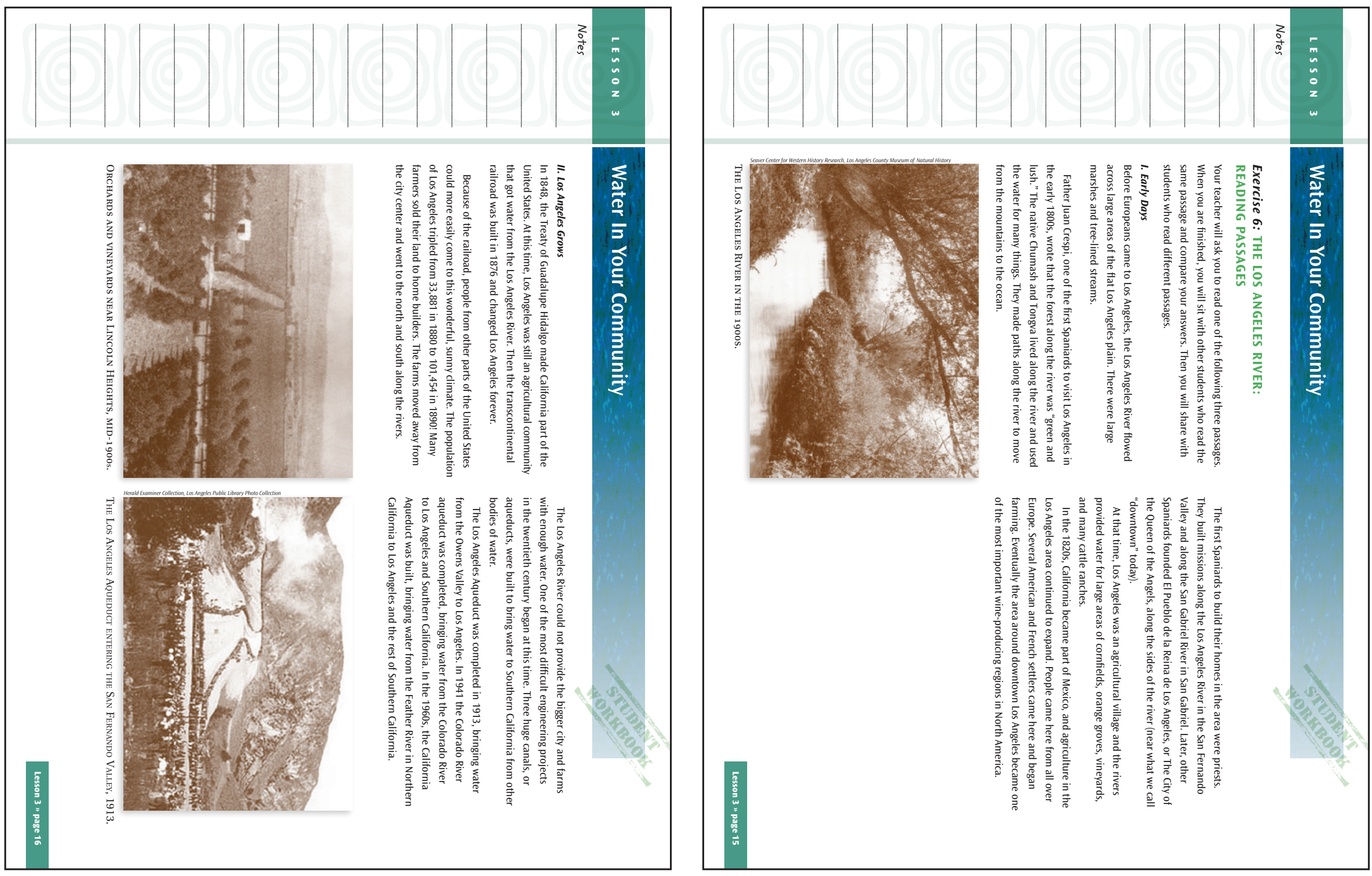


\section{Student Workbook}
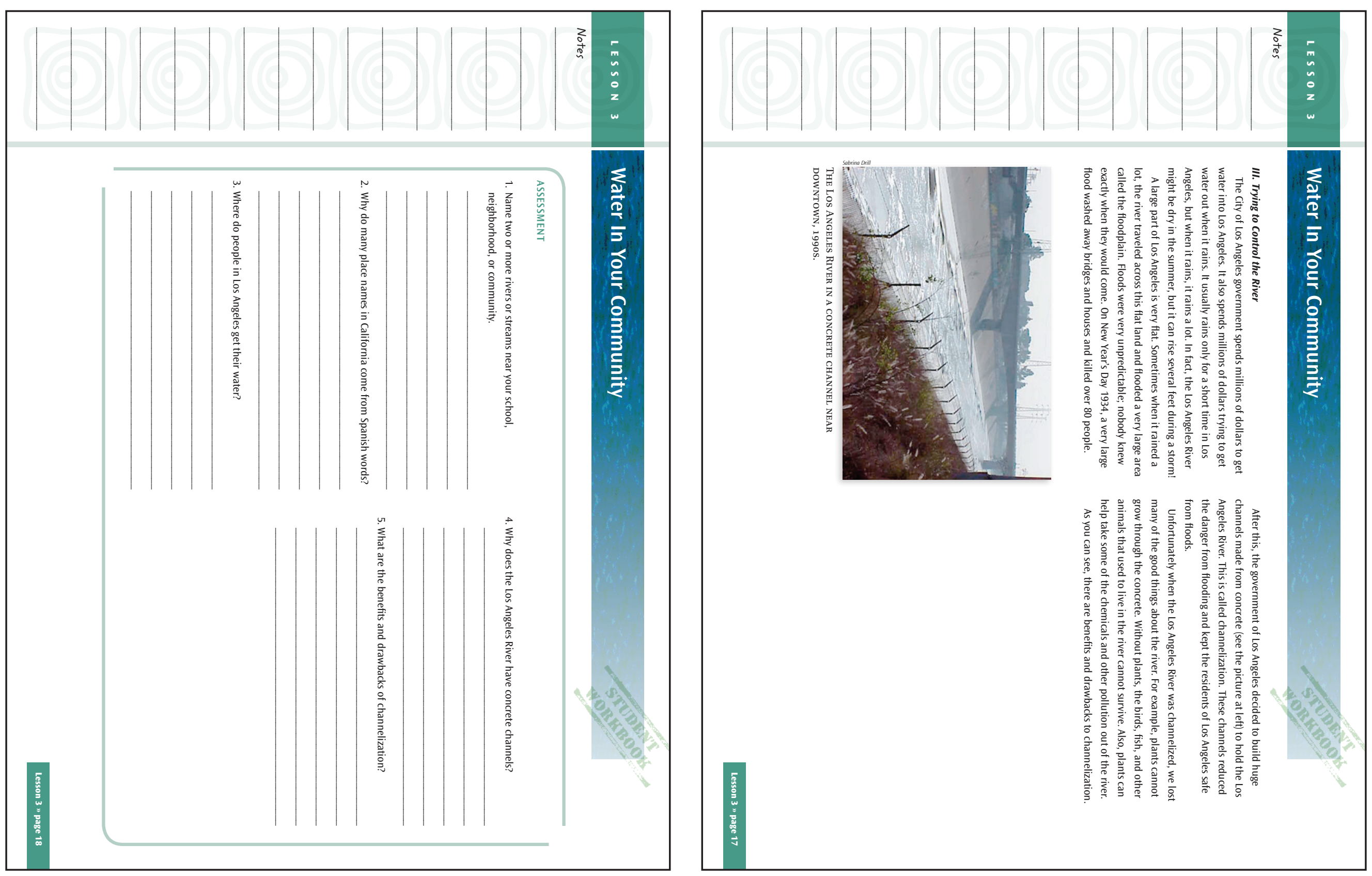


\section{Student Workbook}

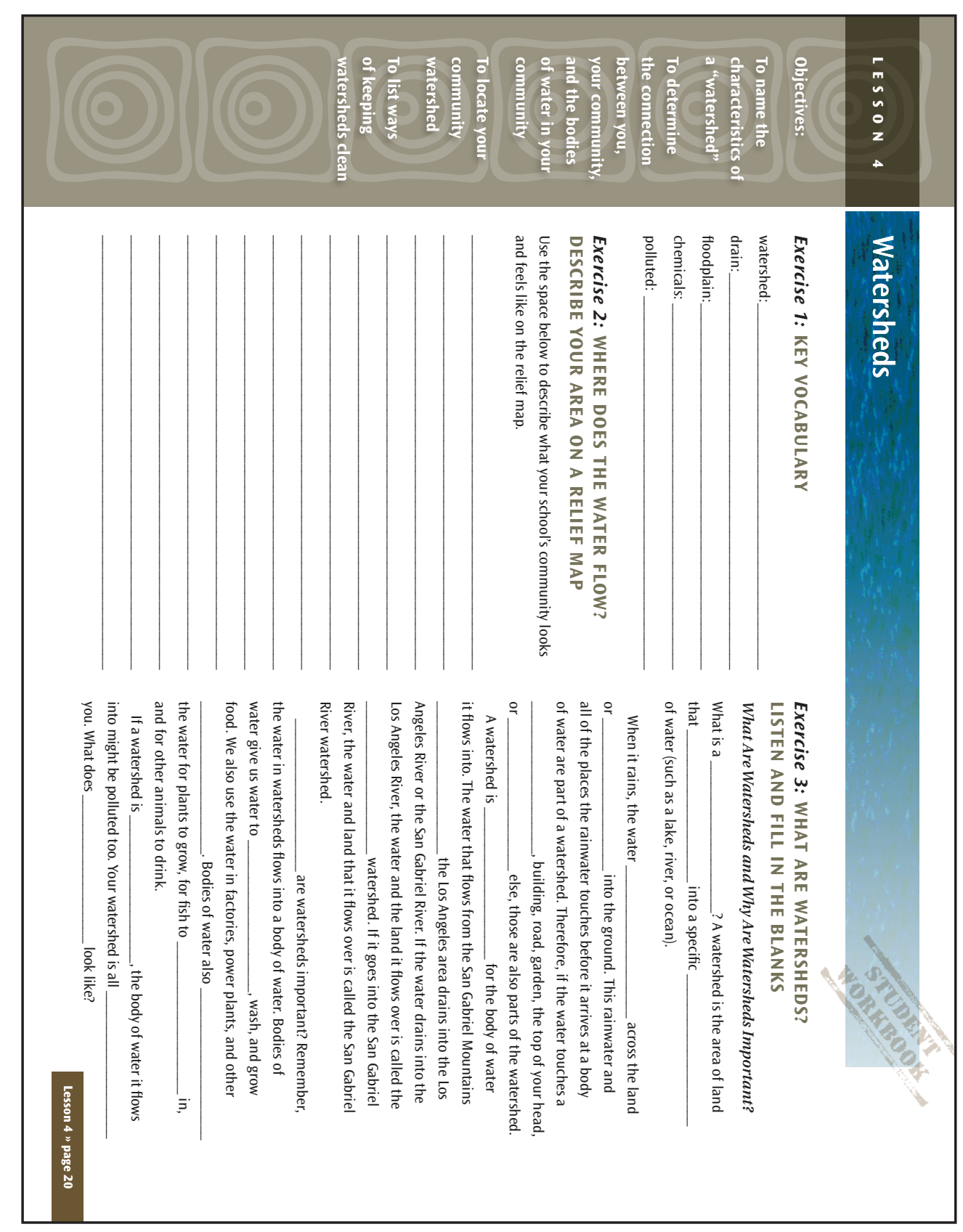

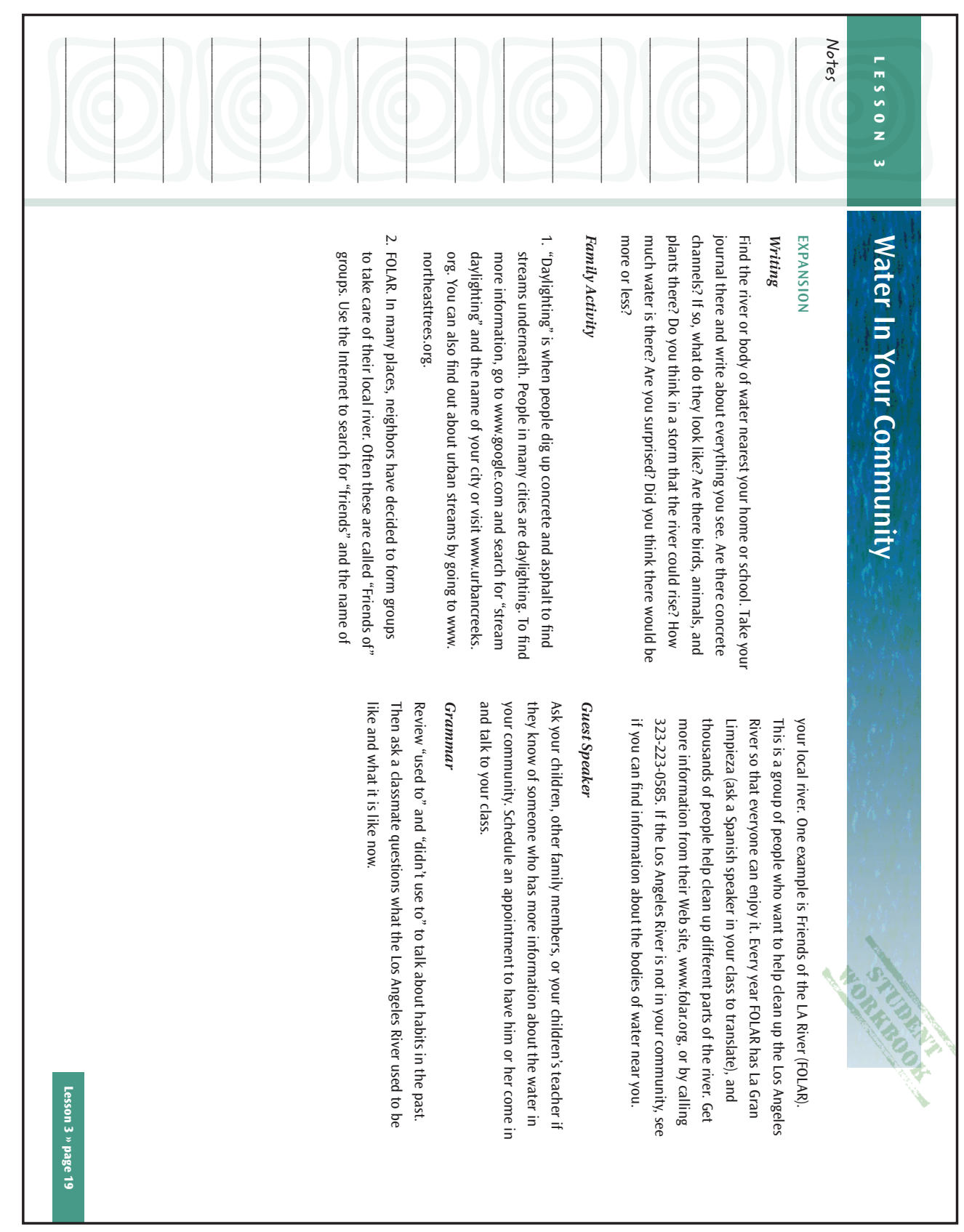




\section{Student Workbook}
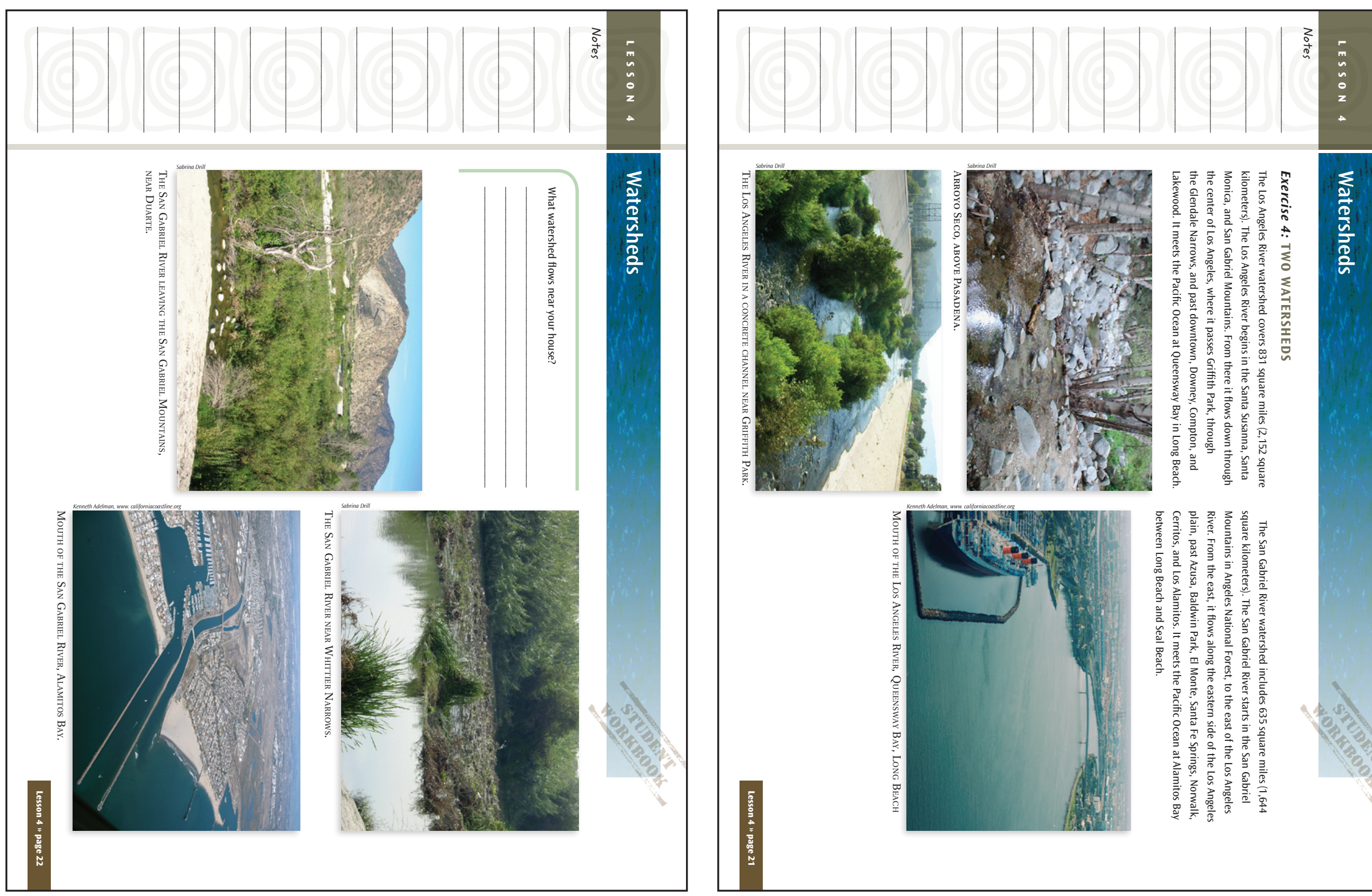

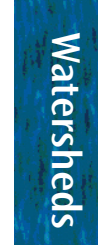

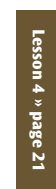

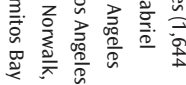




\section{Student Workbook}
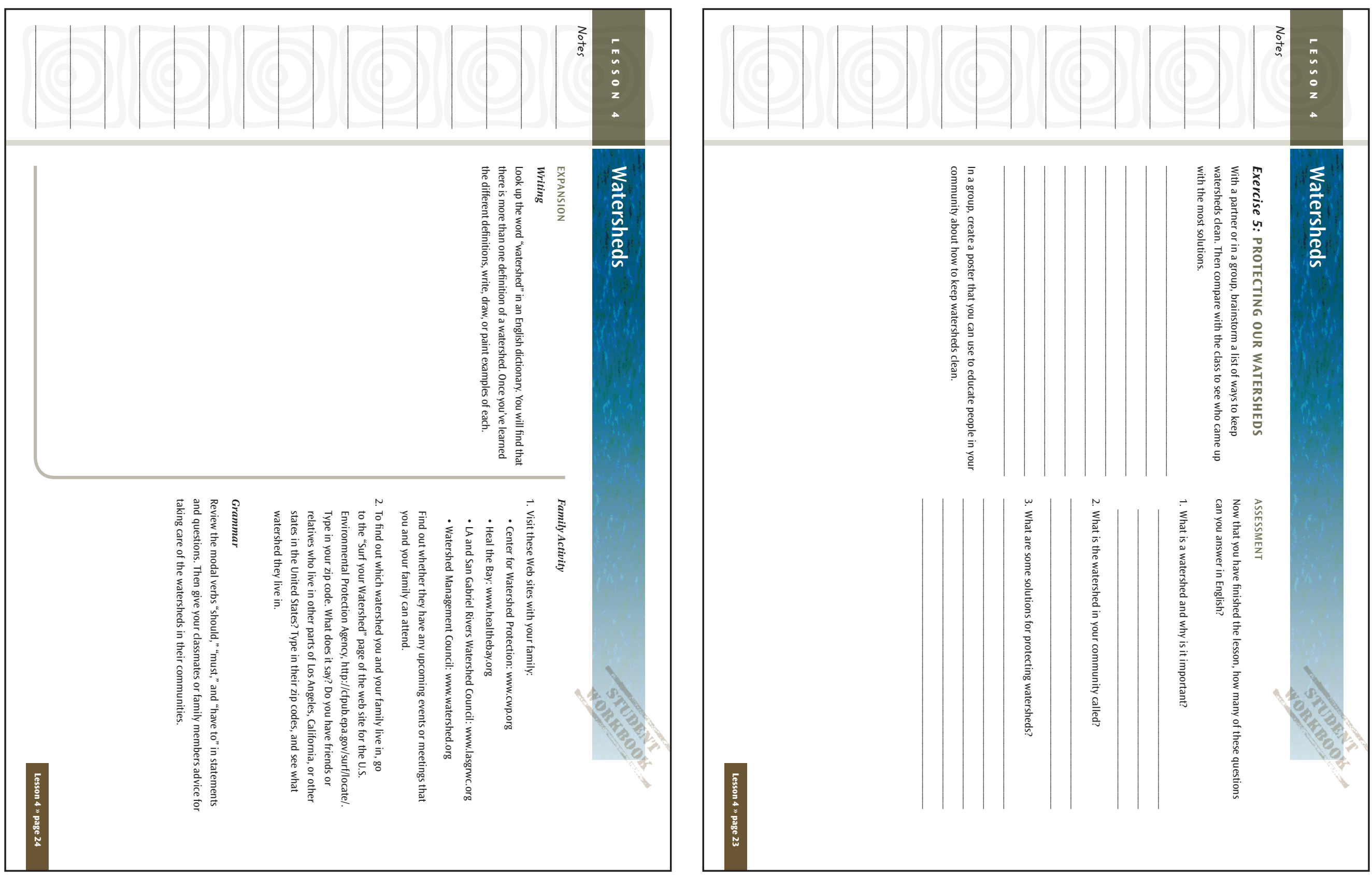


\section{Student Workbook}
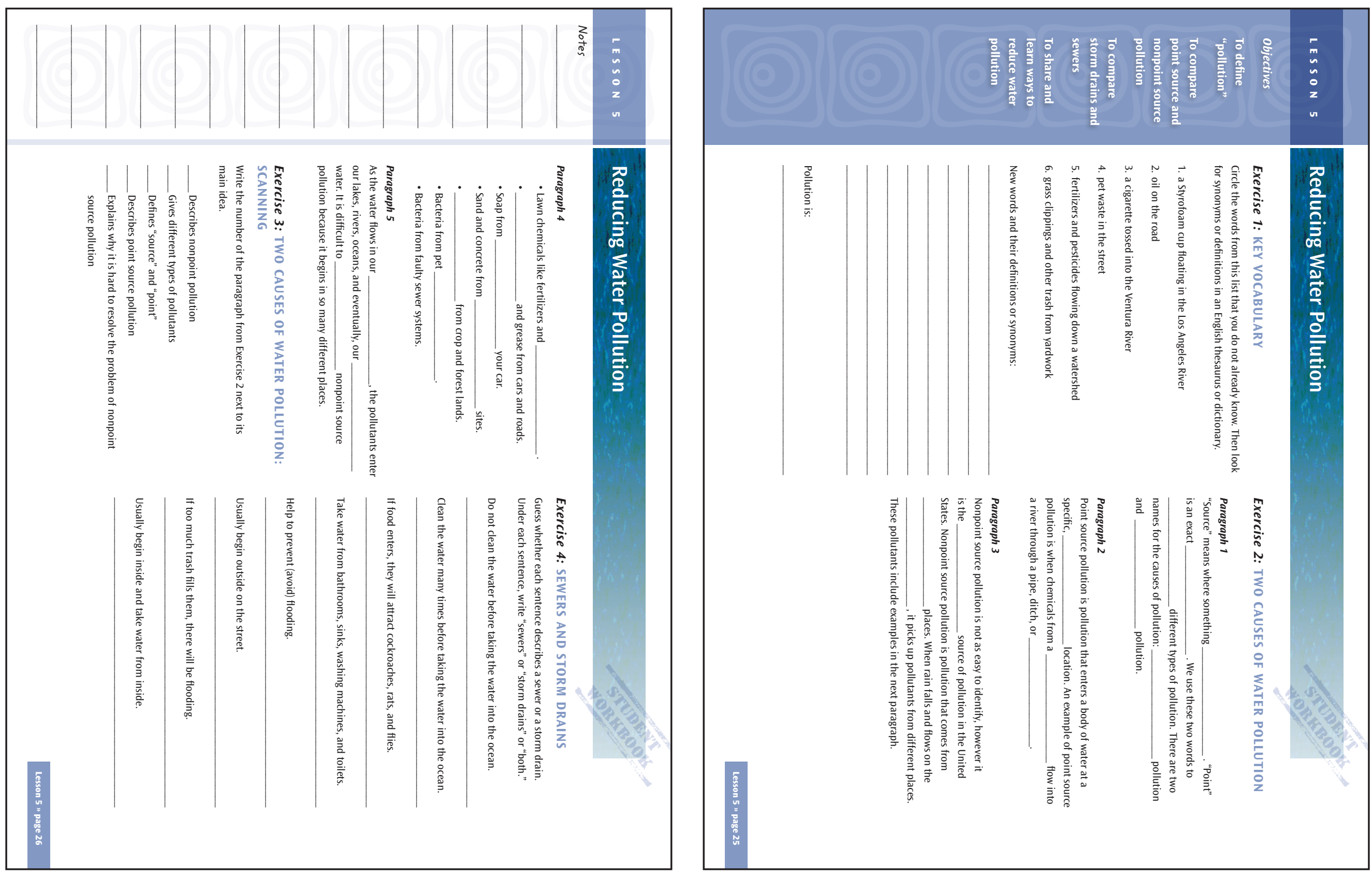


\section{Student Workbook}
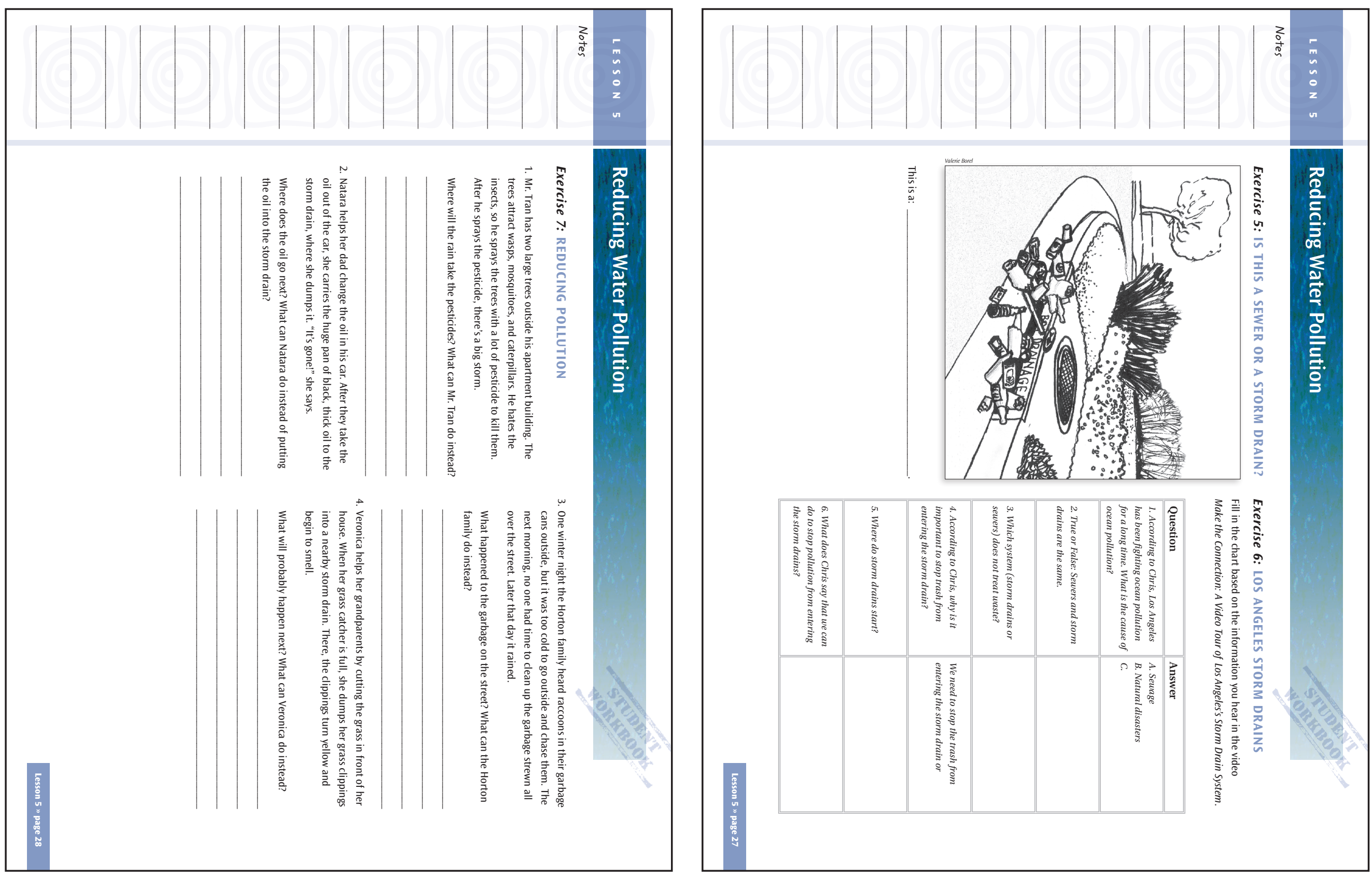


\section{Student Workbook}
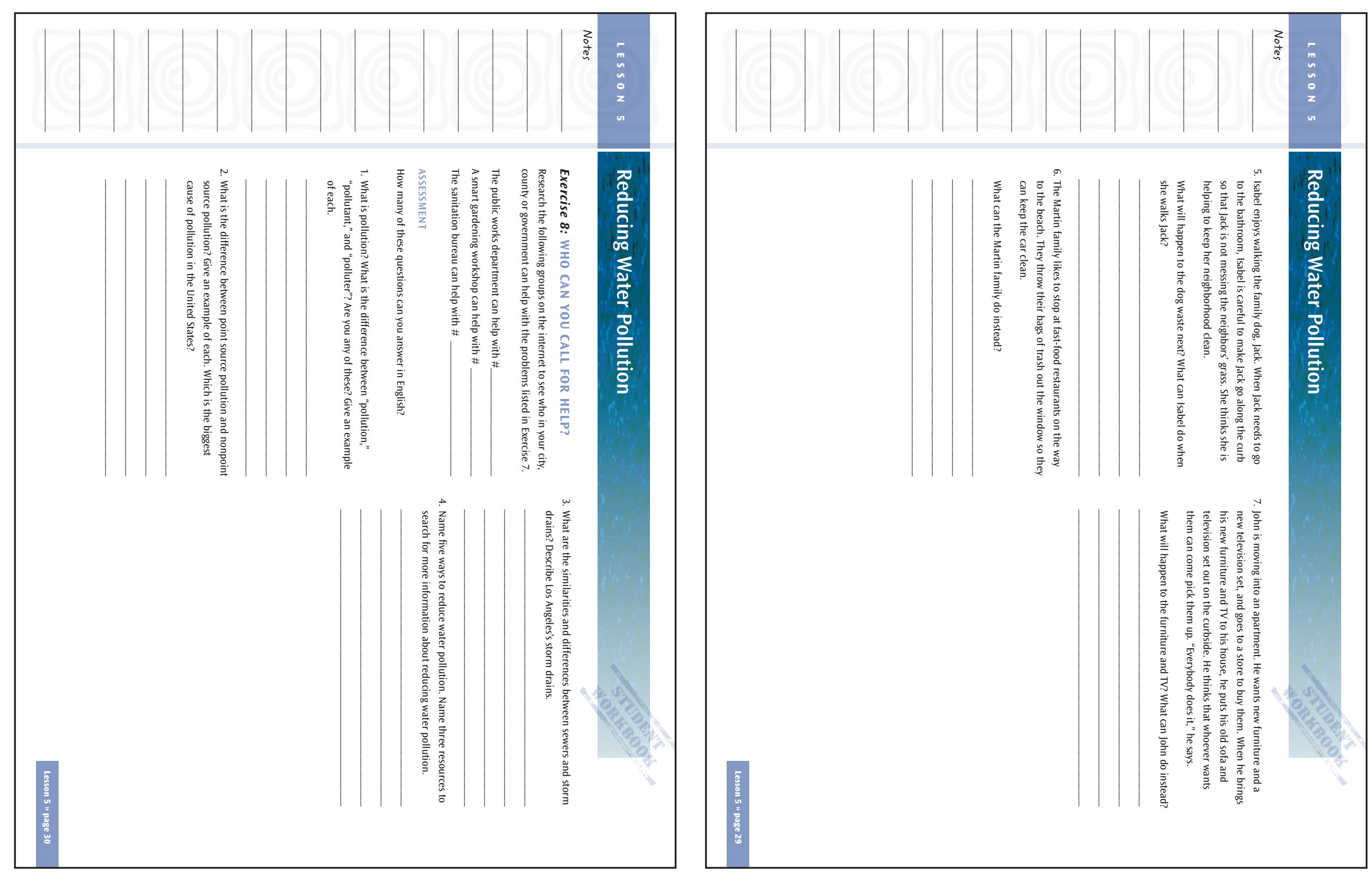


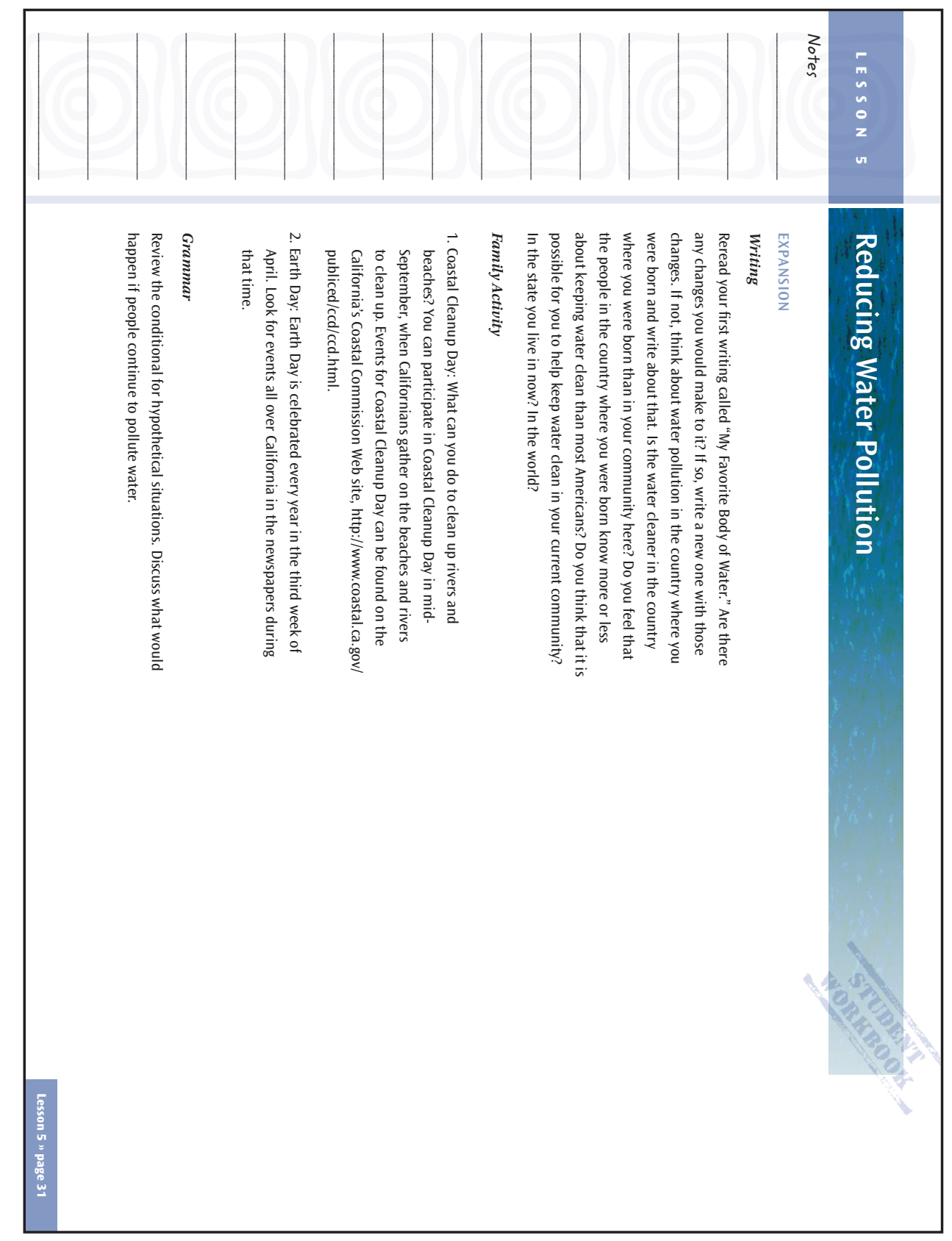



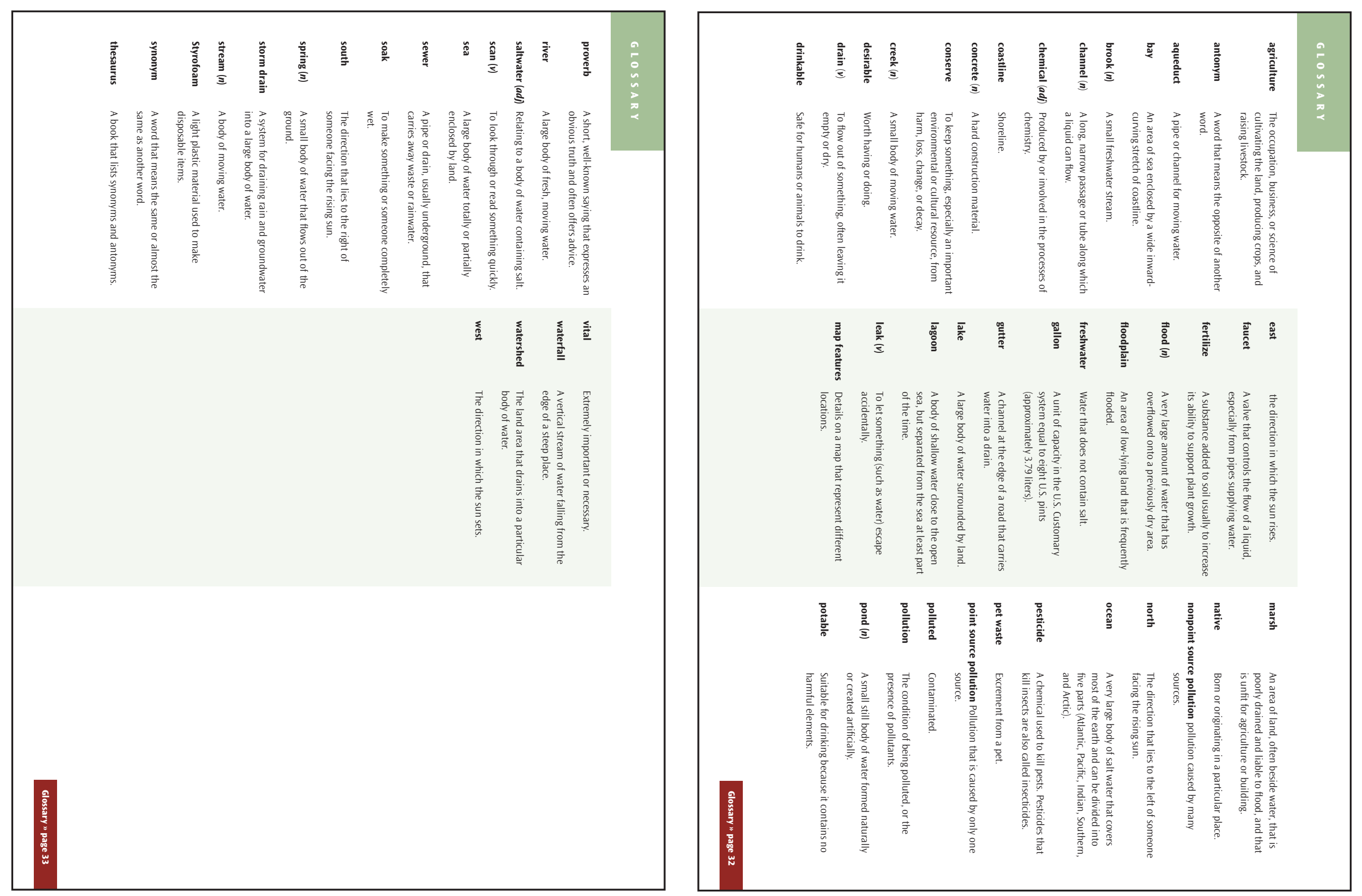


\section{CASAS Civics Objective 23}

\section{Access Community Services Information}

\section{Assessment: Improving the Health of Your Environment}

An environmental problem or situation (in your home or in your neighborhood) requires you to access community resources and services to fix the problem.

Directions: Choose one problem or situation listed below, contact one agency, and ask the question or the problem. Fill in the worksheet on page 60 .

1. The name and location of the community resource.

2. The Web address of the community resource.

3. The telephone number of the community resource.

4. Their hours of operation.

5. State whether the problem or service requires you to fill out an application form and what the form is called.

6. Does the agency have translators or multilingual staff available to help you?

7. By reading their Web site, asking their staff, or reading other information about the community resource or agency, try to list three services that they provide (such as workshops).

8. Do they provide any free equipment, brochures, services, or materials (such as trees) to help you fix the problem, or make available any rebates on materials you need to buy (such as low-flow shower heads)?

Sample problems and agencies to contact:

Problem: "I'm wasting water in my home. How can I conserve water?"

Solution: Contact your water provider or local public works agency. You can find contact information on your water bill or search the Internet. You can also contact the California Flex Your Power Campaign as well as the Metropolitan Water District's Be Water Wise program.

Problem: "Sometimes I see a lot of trash in my neighborhood's streets and alleys. I want to find out more about protecting my storm drains from trash, so that the street doesn't flood when it rains. Can you provide me with more information and publications?"

Solution: Contact your local trash pick-up or public works agency. This may be the same as your water agency. You can also contact the California Integrated Waste Management Board. Find out whether you can get involved in a street, river, or beach cleanup. Many organizations host cleanups for Earth Day, in April, or California Coastal Clean-up Day, in September. Contact the California Coastal Commission for more information or search the Internet for a local group. 


\section{CASAS 23 Assessment Worksheet}

Name:

Class:

Instructor:

Problem

Name of organization

Location

Telephone number

Web site address
Hours of operation

Translators or multilingual staff?

Is an application form required?

What documents are required?

\section{What services do you provide?}

1. 